\title{
Missing Marx: The Place of Marx in Current Communica- tion Research and the Place of Communication in Marx's Work
}

\author{
İrfan Erdogan
}

\author{
Faculty of Communication, Gazi University, Ankara, Turkey, erdogan.irfan@gmail.com, \\ http://www.irfanerdogan.com
}

\begin{abstract}
This study was designed (1) to test Marx's theoretical statements on the nature of dominant ideas in a society by investigating the character of scholarly practices in academic publishing, and (2) to demonstrate the falseness of claims about Marx's disinterest in communication by presenting and evaluating his writings on communication. The study combines quantitative and qualitative methods for data collection and analysis. It has two study populations and multiple samples. The first one includes the articles in communication journals cited by Thomson Reuters' Social Sciences Citation Index. The second one contains all writings of Marx on communication. The findings indicate that (1) the articles are mostly functional to the ruling interests, (2) they mostly exclude Marx and critical issues that question the ruling material and immaterial mode and relations in communication and society, (3) most alternative approaches are controlled alternatives and overtly or covertly directed against Marx's method and explanations. Regarding Marx's interest in communication, contrary to the claims that he had no or minimal interest, Marx provided invaluable explanations about communication. Hence communication scholars should pay close attention if they want to understand the nature and function of communication in society and social change.
\end{abstract}

Keywords: Communication studies, communication theory, Marx, Marxism, Marxist communication studies, communication journals

Acknowledgement: This article is a part of an ongoing study on the current orientations in mass communication theory and research. The Higher Education Council of Turkey funded the collection of data for the project. The author thanks Secil Kentel and Hakan Ugurlu for proofreading the article.

\section{Introduction: The Rationale and Subject of Study}

The control of thought and production, distribution and use of mental products has been one of the main concerns and praxis of the ruling forces throughout human history. As organized life has become complex with deepening inequalities, oppression and unjust distribution of power and wealth, the quantity and scope of the control of thought and behaviour has been expanded to every facet of life. In the $21^{\text {st }}$ century, such control became a nightmarish issue of sustainability in such a way that the management of what, why and how to think and not to think, to feel and not to feel, to believe and not to believe, and to do or not to do was extended to every instance of the daily life of every individual at any age. From the first ancient empires to the demise of feudalism, the mental production, distribution and use were controlled by the theological and political power centres that owned not only the body and souls of the masses, but also the material riches. Then came the "freedom" associated with the capitalist mode of production: The absolute serf or semi-serf found himself/herself free from the yoke of owners/masters and outside and on the street with no means to produce his/her life; his/her freedom turned to be the freedom of owners from responsibilities of keeping a slave; his/her freedom became a new slavery called wage-slavery: He/she had no guarantee of food, clothing and shelter anymore. Those who were doing mental production in the interest of theological and political forces within and outside the church and castles were luckier because new and expanded opportunities, like steadily increasing number of schools and universities and mass media, were emerging outside the traditional centres of mental production. Two basic centres of knowledge production proliferated and gained prominence: (1) corporate research departments and corporate research institutions, and (2) public and private universities. The political, economical and cultural forces gradually started feeling the necessity of complete control of knowledge production, dissemination and use. Capitalism had propagated and strongly stressed the freedom of thought and expression while waging war against feudalism. It turned into a limiter of freedom as soon as people demanded freedom, equality and justice under the capitalist system. Especially since the advent of neo-liberal policies, the control mechanisms were intensified all over the world by (1) the privatization of schools, (2) the marginalization of public education, (3) the revi- 
sions of curricula and educational policies, (4) turning university education into a vocational school level to cater the interests of the corporate world, (5) establishing programs like the Bologna Accord for regional or global standardization that serves specific interests, (6) directing research orientations away from critical inquiry for human development towards the development of institutional and corporate interests, (7) luring scholars towards functional orientations by providing relatively substantial financial rewards via institutional, regional, national, regional and international structures, (8) making some theoretical and methodological approaches dominant and others marginal through reward and punishment mechanisms and through monopoly control of the production, distribution and promotion of academic products, including the promotion and wide distribution of controlled alternatives. In any case, current dominant scholarly orientations in communication are driven by at least three main goals: (1) to climb up the academic ladder, (2) to sustain the prevailing system of personal interest actualisation in the university environment, (3) to get accepted, acknowledged and supported by the established networks of beneficial relations in the university, state institutions, local, regional, national and international foundations, mass media and corporations. The present dominant structure with its controlled-alternatives is a historical condition of dominance and struggle. It is the context of the intensifying political, economic and intellectual crises in the structures, structural relations and institutions of knowledge production. While positivist, empirical and fact-producing quantitative orientations are continuing to stand in the service of industrial interests, newly emerged approaches with the "post" prefix in their names are taking part in the justification, legitimization and mystification of the dominant production mode and relations by emphasizing utmost relativity and particularistic interpretative accounts of micro-units and by ignoring or refusing the unity of the regularities of social relations, their structure, and change and their historical character.

There are many functionalist studies supporting the relationship between universities and industrial structures, we can however see an increasing number of critical analyses on the same subject too (e.g. Schiller 1974; Gans 1975; Gorz 1980; Berube 1995; Martin 1998; Chouliaraki and Fairclough 1999; Cerwonka 2009; Domenech 2009).

All these explanations indicate the existence of the control of mental production by means of numerous mechanisms that integrate private interests with the dominant interests. Furthermore, the control covers every sphere of life: It is actualized not only through the professional practices and professional ideologies, but also through the user choices that are influenced by the character of production, distribution and access. These historically structured mode of relations fall within Marx's theoretical explanation:

"The ideas of the ruling class are in every epoch the ruling ideas: i.e., the class which is the ruling material force of society is at the same time its ruling intellectual force. The class which has the means of material production at its disposal has control at the same time over the means of mental production, so that thereby, generally speaking, the ideas of those who lack the means of mental production are subject to it. The ruling ideas are nothing more than the ideal expressions of the dominant material relationships, the dominant material relationships grasped as ideas; hence of the relationships which make the one class the ruling one, therefore the ideas of its dominance" (Marx 1969, 39).

By using words like "generally speaking," "ruling" and "domination", Marx clearly excludes the one way causal relationship which eliminates the possibility of individual and class struggle via total control. If there was a one way determination and thus total control over minds and behaviour of people, not only the idea of struggle would be invalid but also revolutionary social change would be impossible. If the capitalist class was not interested in controlling the means and content of mental production, there would e.g. be no laws restricting the freedom of thought and expression, the journalists and intellectuals in Turkey would not be in jail waiting for trial more than 4 years, and intellectuals throughout the world would not be silent and apathetic in the face of such a "post-modern civil dictatorship"; the media would not be so acquiescent about oppressive measures and injustices all over the world; the large masses would not be quiet and accommodating; the journalists, intellectuals and academicians would not be talking about the existence of "participatory democracy" despite the obvious fact that they cannot have even a slight influence on the determination of their own salaries; and they would not align themselves with the ruling part of society. There would be no industries like advertising and public relations. Advertisers, agencies like ClA and foundations like Rockefeller and Ford would not spend billions of dollars for mind management.

Derived from the theoretical reasoning and statements above, it is expected that domination manifests itself in the nature of production, dissemination and use of mental products. In terms of 
journal articles, the formation and sustainability of domination includes heavy emphasis on certain theoretical orientations and issues, ample support of functional alternatives, and the elimination, marginalization or distortion of the real alternatives that Marx's approach poses. My study points out that the control of communication via the control of production and dissemination entails not a total control of the minds of people, but the existence of domination and struggle. All the ideas in a society are not and cannot be the ideas of the ruling class. Furthermore, every person carries dominant, conflicting or oppositional ideas to varying degrees. Not every bit of a dominant or oppositional idea can be right or wrong. The main point here is the nature of the connection of ideas to domination and struggle. It is argued that (1) the dominant theoretical and topic orientations of articles in the journals studied are functional for the capitalist mode of production, (2) Marx's theory and method and Marxist issues are mostly excluded from the communication field, (3) most alternatives are not alternatives to the interests of capitalism, but controlled and functional alternatives which are set against one another and especially against Marx and Marxism, and (4) Marx's thinking is represented in the form of false or forged assertions or downgraded by claiming that Marx did not say anything or said very little about communication ${ }^{1}$.

There are three basic aims of the article. The first one is to test the assumption that there are certain dominant theoretical and topic orientations in academic articles in Media and Communication Studies despite the quantitative multitude. The existence of such orientations only means that there is a dominant intersubjectivity feeding certain material and immaterial interests: Even if everybody says that the earth is flat, it does not make the earth flat, but such a claim works only as functional justification.

The second aim is to demonstrate that Marx and issues of the Marxist approach are mostly excluded from Media and Communication studies, and that Marx is invalidated fully or partially, evaluated negatively or criticized for various reasons if he is mentioned in an article. The exclusion or marginalization of Marx in the articles does not mean that Marx's theoretical approach is false or has no value or merit; rather, it means that Marx's approach has thus far been successfully ignored and dismissed with the help of false claims. Such a marginalization and dismissal also indicates and proves the correctness of Marx's analysis of the general character of the ruling ideas. Therefore, the point is not that Marx is wrong, the point is rather that Marx and Marxist issues do not fit the structures of material and immaterial interests, relations and mindsets. They rather threaten the dominant practices. This reminds us of the motto of New York Times: "All the news that's fit to print".

The third aim is to show that the exclusion of Marx entails false justifications like claiming that Marx did not say anything about communication.

The structure of the article is as follow: The first part of the article examines (a) the statistical foundations of the studied topic, and (b) the presence of Marx and Marxism in the analysed articles published in communication journals that are cited in the Social Sciences Citation Index.

The second part of the article presents and discusses Marx's ideas on communication in order to demonstrate that Marx, contrary to prevailing assertions, said a lot about communication.

I used the phrase "missing Marx" in the title in order to indicate that (1) Marx is missing in articles in the "reputable" and the widely circulated journals and that (2) the communication field is missing (needs) Marx, because of (a) the value of his approach, (b) the prevailing domination of certain industry-oriented approaches that ignore or distort significant social and academic issues, (c) the increasing tendency of the usage of "supermarket books" by those who have limited mental comprehension capacities or are simply too lazy to spend time to read anything that forces him/her to think, and (d) the growing influence of popular gurus in communication schools. Unfortunately, "academic fads come and go, the academy becomes complicit in such genuflection, and new gurus emerge and fade" (Tomaselli and Shepperson 2010, 52), but their vestiges or bad copies remain. Being mystified by "body language" and "Neuro Linguistic Programming", and "the unproblematic adoption of decontextualised ahistorical post-structuralist, post-disciplinary" approaches are increasingly encroaching the communication field. ${ }^{2}$

\footnotetext{
${ }^{1}$ Fuchs (2010a) provides a unique answer to this baseless claim by analyzing Marx's writings on communication and systematically presenting them by focusing on the role of media production, circulation and consumption/reception in capitalism.

${ }^{2}$ In 1975 , I had taken courses in communication, political science and research methods at Purdue University and the University of Pittsburgh since 1971. I had never heard of Marx's name in my communication classes and books. I had started searching and found the name of Dallas Smythe and I wrote to him telling him about the missing of Marx in communication courses in my schools and asked for his help in finding Marxist writings on communication. He called me and also gave me Herbert Schiller's name. It was the end of "missing Marx" for me, because Smythe and Schiller suggested to me readings that I had been looking for. Under the prevailing dominant sensitivities and interests, we all miss the "hearts and minds" like Marx, Che, Smythe, Schiller and all those who dedicate their life to the struggle for the freedom and dignity of all human beings.
} 


\section{Theoretical Basis of the Study}

Decent and honourable scholars, like Herbert Schiller, Dallas Smythe, Ariel Dorfman, George Murdock, Peter Golding, Nicholas Garnham and Armand Mattelart in the late 1960s and the following decades, and Dan Schiller, Vincent Mosco, McChesney, Christian Fuchs, Stuart Ewen, Lee Artz, Dyer-Witheford, Richard Maxwell and the like in recent years, have shown that Marx/Marxism is not dead and closely concerned with communication.

The production and distribution of Marx's writings and Marxist texts are also part of the struggle for a better world. Regarding Marx's interest in communication, Fetscher (1969) and Padover (1974) published a collection of Marx's writings on the Freedom of the Press and Censorship. The International Mass Media Research Centre's two books on Communication and Class Struggle, and a book about the Marx's writings on the means of communication are excellent pieces of work. It is not a coincidence that it is difficult to find these books in bookstores and libraries, but only in the personal libraries of people like me.

The present study bases its theoretical framework solely on Marx, thus it is not a classical Marxist, orthodox Marxist, neo-Marxist, autonomous Marxist, post-Marxist or any kind of Marxist study. It tries to clarify the dominant tradition and conscious marginalization of Marx and Marxist oriented studies in the production of knowledge in the leading journals of communication by employing an empirical design. It discusses Marx's approach on communication by presenting his writings that are associated with any aspect and/or type of communication. This presentation will also show the importance of Marx and his approach in the communication field, and will also demonstrate the invalidity, absurdity and ludicrousness of the ideological and propagandist nature of contemporary claims like the end of ideology-hypothesis, the meaninglessness of ideology, or that Marx's analysis was based on economic reductionism, monolithic relations between material conditions of production and mental conditions, the primacy of superstructure or basis, etc.

Marx, as we will see in the following paragraphs, lucidly points out that humans produce their own material and mental life, and they do so in a historical society organized by them. They produce their life conditions by reflecting their thoughts on material conditions and ideas, feelings, values and beliefs. They sustain or change their material and/or immaterial conditions by acting upon them. This theoretical reasoning brings along many conclusions. Some of the conclusions pertinent to the present study are:

(1) The claims about Marxist reflectivity are false explanations, because we could never establish, develop and change life, make history and engage in the struggle for liberation if our thoughts were mere reflections of our material life. Marx talks about the dominant mode of production and relations and reminds us about the lasting existence of remnants of the old material and especially immaterial relations. One of the best examples is that the capitalists who rule the world today support the governments of theological political parties that come to power exploiting the religious and irrational beliefs of people. Marx argues: "the individuals composing the ruling class [...] among other things rule also as thinkers, as producers of ideas, and regulate the production and distribution of the ideas of their age: thus their ideas are the ruling ideas of the epoch" (Marx 1969, 39). [We go astray] "if [...] we detach the ideas of the ruling class from the ruling class itself and attribute to them an independent existence, if we confine ourselves to saying that in a particular age these or those ideas were dominant, without paying attention to the conditions of production and the producers of these ideas, and if we thus ignore the individuals and the world conditions which are the source of these ideas" $(1964,79)$.

(2) The ideas of economic determinism, reductionism or technological determinism are not immanent in Marx's works. For instance, a statement like "the traditional Marxist approach postulates a mechanical relation between economic structure and socio-cultural superstructure" (Grossberg, 1997, 22) is nonsense and a classic cold-war ideological propaganda for mind management geared toward unaware readers, students and academicians. It knowingly or unknowingly distorts the basic theoretical structure of Marxism. Marx commented that his work merely attempted to describe the path that Western capitalism developed from feudalism, and that one should not "transform his historical sketch of the development of Western European capitalism into historical-philosophical theory of universal development predetermined by fate for all nations, whatever their historic circumstances in which they find themselves may be. [... that view] does me at the same time too much honour and too much insult' (Padover 1979, 321). Engels provided a clear explanation for the same issue in a letter to Bloch in 1890:

"According to the materialist conception of history, the ultimate determining element in histo$r y$ is the production and reproduction of real life. More than this neither Marx nor I have ever asserted. Hence if somebody twists this into saying that the economic element is the only determining one, he transforms that proposition into a meaningless, abstract, senseless 
phrase. The economic situation is the basis, but the various elements of the superstructure political forms of the class struggle and its results, to wit: constitutions established by the victorious class after a successful battle, etc., juridical forms, and even the reflexes of all these actual struggles in the brains of the participants, political, juristic, philosophical theories, religious views and their further development into systems of dogmas - also exercise their influence upon the course of the historical struggles and in many cases preponderate in determining their form. There is an interaction of all these elements, in which, amid all the endless host of accidents (that is, of things and events whose inner interconnection is so remote or so impossible of proof that we can regard it as non-existent, as negligible) the economic movement finally asserts itself as necessary. Otherwise the application of the theory to any period of history would be easier than the solution of a simple equation of the first degree" (Marx and Engels 1962, 488).

(3) Technological determinism is an immanent element of the approaches of popularized stars like Daniel Bell, Marshall McLuhan and new popular gurus, who claim that the Internet brings about an "information and knowledge society" and "democratization". Contrary to the currently popular technological determinist idea establishing a causal connection between the Internet and the socalled information and knowledge society, a society becomes a knowledge society (a) only if the Internet provides "information and knowledge" which is functional to general interests and goes beyond controlling the interests, minds and behaviours of the millions via capturing and imprisoning them in front of a monitor and beyond marketing material and mental end-products of capitalist enterprises and institutions, and (b) only if people use the Internet to make sound decisions on meeting their daily rational needs. Democratization requires not only participation in public discussions, but also, most importantly, affecting the political and economical decision making processes. In short, as scholars like Herbert Schiller, Dan Schiller, Christian Fuchs, Vincent Mosco, Peter Golding, Nicholas Garnham and Dyer-Witheford vividly demonstrate, the Internet represents a new sphere and an extension of ongoing domination and struggle. In any case, the so-called information society, knowledge society or service society is still a capitalist society and the claim of "democratization" via the Internet is the acknowledgement that capitalist society is not a democratic society and was waiting for the Internet to rescue capitalism from such burden.

(4) Marx neither ignores nor downgrades ideology in his explanations in The German Ideology and other writings and does not assign a determining or dependent position to it.

(5) Claims like the ones that we have reached an "end of ideology" and "of grand narratives/theories" are ideological and function as tools for justifying various policies, including the "war against terror" ideology that helps to evade and ignore the ongoing terrorism in the workplace and of industrial policies. Ideology primarily means two things: (a) the structure of ideas/thoughts and (b) the study of ideas (just as sociology is the study of the "social"). "No ideology" or the "end of ideology" simply means "no idea", "no thought", "end of thinking", or "end of ideas". But no human being and organized human life could exist, if there were no idea/thinking/thought and structure(s) of ideas. "The end of ideology" (or the end of history or the claim of discontinuity that postmodernism is not a continuation of modernism) is the ideology of the global capitalism that institutes functional ignorance as knowledge. The justifications by establishing connections with grand theories, disintegration of the Soviet System, modernist era or any other things are simply forged factoids.

\section{The Method of the Study}

The study was designed as a combination of quantitative and qualitative research. The concept of method used here refers only to processes of data collection and analysis. The use of empirical data and statistical measures does not make a study a positivist-empirical research: A mainstream scholar designs a study based on a certain theoretical reasoning, collects and analyzes empirical data, and suggests that, for instance, it is necessary to establish water treatment plants to clean the polluted river. A Marxist scholar designs a study based on the Marxist theoretical framework, uses the same empirical process to collect data and even statistically analyze the data, and suggests that it is necessary to change the relations and processes of production in such a way that the river does not get polluted and we get clean water at any point of the river. We can prepare a survey questionnaire to analyse the attitudes, opinions and evaluations of workers in order to help a corporation's policies or in order to support whatever is right. Marx himself conducted critical empirical research when he e.g. prepared a survey questionnaire in 1880 . It was distributed to 25,000 French workers to determine the working conditions and raise questions in the minds of workers about their working conditions and the issues presented in the questionnaire (Bodemann 1979; Babbie 2004, 243; Dei and Johal 2005). 


\subsection{Scope of the Study}

The scope of the study covers articles about Marx in the communication journals cited in the Social Sciences Citation Index and Marx's ideas about communication.

Studying the nature of communication research orientations requires examination of published journal articles, books, master and doctoral theses, and institutional and industrial study reports. This task takes substantial time, money and intellectual workforce. This pressing fact required limiting the study to journal articles.

There are most probably more than a thousand journals carrying at least one article concerned with communication issues from time to time. However, the present study defines its study population as journals cited in the Social Sciences Citation Index that are accepted as "core journals", the "nerves of the discipline", "the barometer of the substantive focus of scholarship and research methods" most important to the communication field (Potter and Riddle 2007), and a measure of academic scholarship by universities throughout the world. There are also journals with critical and historical/dialectical materialist theoretical orientations, but we can hardly find such journals in the dominant control centres of the production and distribution channels. The ones that exist are most probably either functional-critical or quasi-critical ones or they represent controlled alternatives that are used for the legitimization of the prevailing dominant practices and the de-legitimization of real alternative sources and of products that are based on Marx's approach. Sure, there is a high possibility that we can find, as Herbert Schiller pointed out once (Schiller and Pool 1981) "one pearl in ten truckloads of garbage", however, this only supports Marx's point and does not prove the existence of freedom of expression, equal opportunities and the like.

\subsection{Determining Data and Information Sources}

The first part of the study is designed to investigate the nature of the use of Marx. It requires an examination of published journal articles, books, master and doctoral theses, and institutional and industrial study reports. This task takes a lot of time, money and intellectual workforce. That is why the articles were selected by considering the fact that journal articles provide us with the most upto-date knowledge about the subject in question.

There were over 800 journals in the Communication and Mass Media Complete Database Coverage List (EBSCO Publishing) ${ }^{3}$, Proquest ${ }^{4}$ and SSCI in 2011 . However, there were only 85 journals classified as communication journals in the Social Sciences Citation Index ${ }^{5}$. Six non-English and two journals were excluded from the study (Circulo De Linguistica Aplicada A La Comunicacion, Comunicacion Y Sociedad, Comunicar, Estudios Sobre EI Mensaje, Javnost-The Public, Tijdschrift Voor Communicatiewetenschap, Journal of the SMPTE, and Text and Performance Quarterly), and, thus, total 77 journals were selected for the investigation.

The second part of the study focuses on examining the relevance of Marx in the communication field by challenging the claim that Marx said nothing or very little about communication or that his works have no significance for discussing communication. In order to demonstrate that Marx provided significant explanations, all the available writings of Marx were used to find and evaluate Marx's statements concerning communication.

\subsection{Population, Sample, Data Collection and Analysis}

The study population includes articles published between January 2007 and June 2011 in the 77 selected journals (table 1).

More than one method was used for the data collection:

(1) In order to find out whether or not the articles used the Marx's name or Marxism in their main text, the whole population (10104 articles) was used in the data collection and analysis.

(2) In order to analyze the nature of use of Marx, all the articles that mentioned Marx's name in their full text were filtered out (210 articles out of 10104).

(3) In order to determine the general profile of the studied journals, the first article of the first issue of each year was selected in the study and, as a result, 385 articles from the 77 journals were coded and analyzed.

(4) In order to analyse topics of studies, the first article of the each issue was selected, which amounted in 1386 articles.

\footnotetext{
${ }^{3}$ http://www.ebscohost.com/academic/communication-mass-media-complete; http://www.ebscohost.com/titleLists/ufhcoverage.htm

${ }^{4}$ http://www.proquest.com/en-US/catalogs/databases/detail/commabs-set-c.shtml

5 http://science.thomsonreuters.com/cgi-bin/jrnlst/jlresults.cgi?PC=J
} 
Only the research articles were used for the study. Editorials, editors' reports/comments, book reviews, articles labelled as "research in brief" or given similar designations and the like were excluded from the study.

\begin{tabular}{|c|c|}
\hline 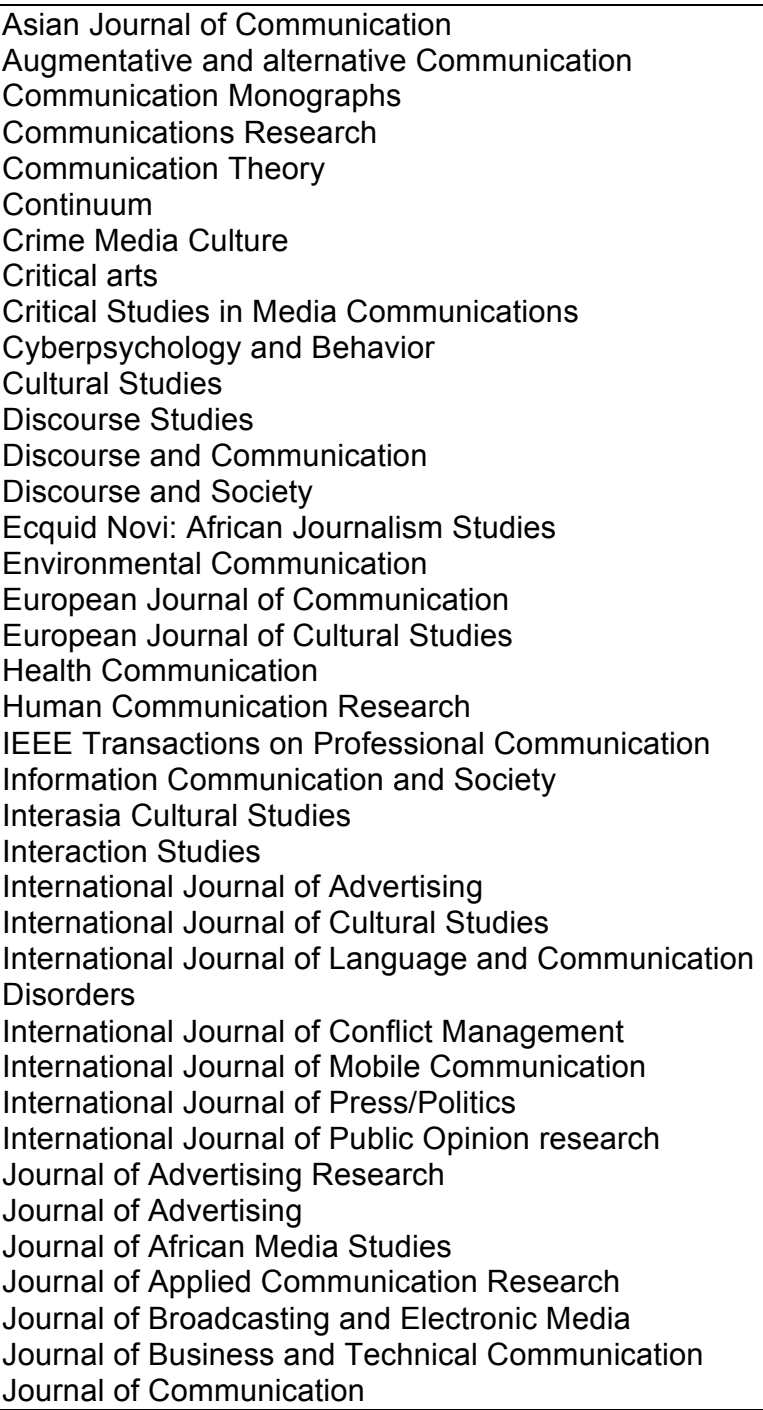 & $\begin{array}{l}\text { Journal of Communication Disorders } \\
\text { Journal of Computer-Mediated Communication } \\
\text { Journal of Health Communication } \\
\text { Journal of Media Economics } \\
\text { Journal of Mass Media Ethics } \\
\text { Journal of Language and Social Psychology } \\
\text { Journal of PR Research } \\
\text { Journal of Social and Personal Relationships } \\
\text { Journalism and Mass communication Quarterly } \\
\text { Journalism Studies } \\
\text { Language and Communication } \\
\text { Language and Intercultural Communication } \\
\text { Language and Speech } \\
\text { Management Communication Quarterly } \\
\text { Mass Communication and Society } \\
\text { Media Culture and Society } \\
\text { Media International Australia } \\
\text { Media Psychology } \\
\text { Multilingua } \\
\text { Narrative Inquiry } \\
\text { New Media and Society } \\
\text { Political Communication } \\
\text { Public Understanding of Science } \\
\text { Public Culture } \\
\text { PR Review } \\
\text { PO Quarterly } \\
\text { Quarterly Journal of Speech } \\
\text { Personal Relationships } \\
\text { Research on Language \& Social Interaction } \\
\text { Rhetoric Society Quarterly } \\
\text { Science Communication } \\
\text { Screen } \\
\text { Technical Communication } \\
\text { Telecommunications Policy } \\
\text { Text and Talk } \\
\text { Theory Culture and Society } \\
\text { Television and New Media } \\
\text { Visual Communication } \\
\text { Written Communication } \\
\end{array}$ \\
\hline
\end{tabular}

Table 1: Journals included in the study

Indicators of variables were tentatively assigned and new indicators were added in the process of data collection and data coding.

Basic orientations: Basic orientations included the publisher, basic types of communication (technologically mediated or not), study objectives, basic methodological structures and levels of study.

The use of Marx and Marxism: Identified were (1) the distributional share of the use of Marx and Marxism in all the journals that contain 10104 articles and (2) the nature of use of Marx and Marx's writings in the articles.

Theoretical orientations: The analysis included the determination and analysis of the distribution and nature of theoretical orientations of articles.

Issues studied: This analysis focused on the discussed issues.

The analysis was conducted with the help of quantitative and qualitative content analysis. The quantitative part dealt with the presentation and discussion of the distributional characteristics of data. Distributional characteristics were determined by frequency and dispersion analyses in order to test if Marx's statement holds true in the sense that the control of thoughts, beliefs and feelings are exercised through the nature of theoretical, issue and content orientations. The qualitative part was the logical evaluation of the quantitative and qualitative data collected from Marx's published materials. 


\section{Findings and Evaluations}

\subsection{Basic Orientations}

\section{Publishers}

There were 25 publishers of the 77 journals. The leading ones are Routledge (Taylor \& Francis) $(29.9 \%)$ and Sage $(28.6 \%)$. The rest follows far behind, ranging from $5.2 \%$ to $1.3 \%$. This finding reflects the fact that Routledge and Sage dominate the international publishing business. Dominating the world's journal (and book) publishing market, Routledge publishes over 2878 journals (http://www.tandfonline.com). Sage is the world's 5th largest journal publisher and its publications include more than 645 journals spanning the Humanities, Social Sciences, as well as Science, Technology, and Medicine. More than 280 Sage journals are published on behalf of 225 learned societies and institutions (http://www.sagepub.com/journals.nav). The extent of the publishers' role in the ideological control of scientific production and dissemination in the communication field requires investigation. One claim is that the worldwide circulations of, e.g., books like "Four Theories of the Press" in the early 1960s and recent "critical" or "alternative" books are not produced primarily with ideological motives. The basic idea is that publishers do not care about the ideological content. Their main motive is material profit, and thus, they sell anything that helps them make money. This is certainly true. However, the historical experiences indicate that the ideological interest of the capitalist class (including feelings, religious beliefs and war against the "enemy") becomes a ruling concern when the sustainment of capitalism is at stake. Capitalists invest (and donate) a good deal of money for the sustainable development of their local, national and global domination.

\section{The Forms of Communication (Technologically Mediated or Not)}

Over half of the 1386 studies $(59.4 \%)$ are about technologically mediated communication, while $17.0 \% \%$ focus on technologically unmediated communication (mostly self-communication and interpersonal communication). $23.6 \%$ deal with no types of communication, but communicationrelated concepts, methods, theories, issues or processes. Traditional mass communication still occupies half $(49.9 \%)$ of the articles focused on technologically mediated communication (table 2 ). Computer mediated communication follows far behind (13.6\%).

\begin{tabular}{|l|r|r|}
\hline Mediated communication & $\mathbf{N}$ & $\%$ \\
\hline Mass communication in general & 184 & 22.4 \\
\hline Newspapers/journalism & 62 & 7.5 \\
\hline Radio & 10 & 1.2 \\
\hline Television & 82 & 10.0 \\
\hline Cinema/film & 53 & 6.4 \\
\hline Magazines, journals & 4 & 0.5 \\
\hline Books, novels & 4 & 0.5 \\
\hline Music & 6 & 0.7 \\
\hline Advertising and marketing communication & 54 & 6.6 \\
\hline Public relations & 21 & 2.6 \\
\hline Political communication via the media & 7 & 0.9 \\
\hline Computer mediated communication & 112 & 13.6 \\
\hline Mobile communication & 22 & 2.7 \\
\hline Telecommunication & 11 & 1.3 \\
\hline Human - robot communication & 7 & 0.9 \\
\hline $\begin{array}{l}\text { Others (technologically mediated): e.g., self, personal communi- } \\
\text { cation, interpersonal, group, organizational, technical, technol- } \\
\text { ogy, professional communication }\end{array}$ & 184 & 22.4 \\
\hline & & \\
\hline
\end{tabular}

Table 2: Distribution of technologically mediated communication 


\section{Study Objectives}

There are great varieties of objectives of the analysed articles. However, over half of them (55.8\%) do not state their objectives. Furthermore, $15.6 \%$ of the statements of objectives are not objectives, but statements or restatements of methods. Hence, the study shows that only $28.6 \%$ of all studies have a valid objective. Most objectives are effect and individual/receiver related. Very few "alternative" studies set as an objective to question the industrial structure, whereas most of them come up with objectives that focus on various identity issues (except class identity) and stress the invalidity of class analysis and the euro-centrism of Marx's approach.

\section{Methodological Structure}

The findings show that $65.2 \%$ of the studies have mainstream orientations $(23.5 \%$ are administrative research and $15.5 \%$ are primarily academic, but serving industrial or institutional interests). There are studies that question the dominant structures and relations (e.g., media portrayal, identity, identity politics), and Marx and Marxist approaches. Such studies (postmodern, post-positivist, post-constructivist, post-colonialist, post-structuralist, liberal-pluralist and the like) occupy a little more than one fourth of all studies (27.5\%). Studies that use a Marxist methodology (excluding post-Marxism) account for only $7.3 \%$.

A wide variety of qualitative designs dominates the studies $(61.0 \%)$, followed by positivistempiricist quantitative designs $(39.0 \%)$.

About three quarters $(73.5 \%)$ of the quantitative studies are quasi-experimental single survey research. Quasi-experimental lab/clinic design occupies $25.9 \%$. True experimental design amounts for only $0.6 \%$. There is no true experimental design (lab or clinical) in mass communication research. Qualitative mass communication studies are mostly either parametric or non-parametric survey designs. There is a tendency toward developing measurement devices and validating them. However, this tendency is at a marginal level, since most studies still use Likert-type measures.

The quantitative studies are mostly at the exploratory descriptive assessment level (39.0\%), followed by a causal/inferential design (32.2\%), and a bivariate relational design (23.2\%).

Almost all descriptive studies break a basic scientific rule: A study design at this level requires that there should be no or insufficient accumulation of knowledge in the state of the art of the research topic or a need to question the existing knowledge. Generally, the bivariate studies have serious methodological problems: they just compare variables and state relationships without a correlation design that requires relational hypotheses. Inferential/causal studies employ multivariate or factor analysis, but most of them have no hypotheses that require multivariate or factorial analysis.

All of these are indeed serious methodological problems, in addition to the fact that most studies are focused on the analysis of audiences/consumers for marketing purposes.

\subsection{The Use of Marx and Marxism}

As specified in the introduction, it is expected that use of Marx and Marxism in the analysed articles is at a marginal level and that the nature of use is negative. The findings below support such assumptions.

\section{Using Marx's Name}

Marx and Marxism occupy extremely marginal space in the journals. Of the 10104 articles published between 2007 and mid 2011 in communication journals, only $210(2.1 \%)$ include the name of Marx and $450(4.5 \%)$ contain Marx's name or the word "Marxism" at least once in the main text.

39 journals and 210 articles mention Marx's name in their main text. The great majority of these 210 articles uses Marx's name once (57.6\%), twice (14.8\%) and 3-5 times (14.8\%). Although $2.1 \%$ of 10104 articles mention Marx, most of them are mere usages of his name as a part of their narration.

Theory, Culture and Society published over one fourth of the 210 articles $(26.7 \%)$, followed by Cultural Studies (11.0\%), Interasia Cultural Studies (6.7\%), Rhetoric Society Quarterly (3.8\%), Media, Culture and Society (3.3\%), Communication Theory (3.3\%), Continuum (3.3\%), and Public Culture $(2.9 \%)$ respectively.

There are just 15 articles that deal completely or mostly with Marx, of which 8 were published in Theory, Culture and Society, and 2 in Cultural Studies.

The chart below (figure 1) clearly shows the highly skewed distribution based on 210 articles $(2.1 \%$ of 10104$)$ that use Marx's name. 


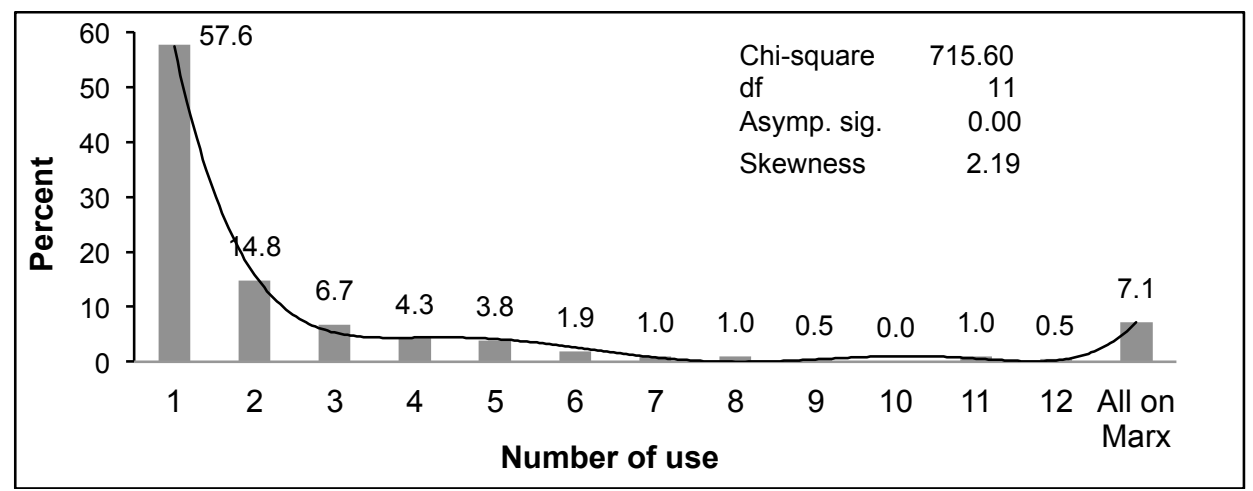

Figure 1: Number of time Marx's name was used in the main text

The findings above and the highly skewed distribution shown in figure 1 point out that the articles very rarely use or even mention Marx. However, the unexpected result is that Marx's name occupies a marginal place in the journals that feature mostly "critical articles". Table 3 shows that Marx appears at least once in $56(22.7 \%)$ of 247 articles in Theory, Culture \& Society and the great majority (47 of 56 ) merely mentions Marx's name 1-3 times. This rate decreases to $13.5 \%$ in Cultural Studies, $10.0 \%$ in Rhetoric Society Quarterly, 9.7\% in Interasia Cultural Studies, $4.6 \%$ in Critical Studies in Media Communication, and 3.3\% in Media, Culture and Society.

\begin{tabular}{|c|c|c|c|c|c|c|c|c|c|c|c|c|c|c|c|c|c|}
\hline & \multicolumn{13}{|c|}{ Number of uses } & \multirow[b]{2}{*}{$\begin{array}{l}\text { Row } \\
\text { total }\end{array}$} & \multirow[b]{2}{*}{$\begin{array}{c}\text { Row } \\
\%\end{array}$} & \multirow[b]{2}{*}{$\begin{array}{c}\mathrm{N} \text { of } \\
\text { articles } \\
\text { analyzed }\end{array}$} & \multirow[b]{2}{*}{$\begin{array}{c}\% \\
\text { use } \\
\text { Marx } \\
\end{array}$} \\
\hline Journals & 1 & 2 & $3-5$ & $\begin{array}{r}6- \\
12\end{array}$ & a & b & c & d & e & f & g & h & $\mathbf{i}$ & & & & \\
\hline Asian $\mathrm{J}$ of Communication & 2 & 1 & 0 & 0 & 0 & 0 & 0 & 0 & 0 & 0 & 0 & 0 & 0 & 3 & 1.4 & 104 & 2.9 \\
\hline $\begin{array}{l}\text { Communication Mono- } \\
\text { graphs }\end{array}$ & 1 & 0 & 0 & 0 & 0 & 0 & 0 & 0 & 0 & 0 & 0 & 0 & 0 & 1 & 0.5 & 104 & 1.0 \\
\hline Communication Theory & 2 & 3 & 1 & 1 & 0 & 0 & 0 & 0 & 0 & 0 & 0 & 0 & 0 & 7 & 3.3 & 96 & 7.3 \\
\hline Continuum & 3 & 3 & 1 & 0 & 0 & 0 & 0 & 0 & 0 & 0 & 0 & 0 & 0 & 7 & 3.3 & 247 & 2.8 \\
\hline Crime Media Culture & 2 & 0 & 2 & 1 & 0 & 0 & 0 & 0 & 0 & 0 & 0 & 0 & 0 & 5 & 2.4 & 65 & 7.7 \\
\hline Critical arts & 1 & 2 & 0 & 1 & 0 & 0 & 0 & 0 & 0 & 0 & 1 & 0 & 0 & 5 & 2.4 & 81 & 6.2 \\
\hline $\begin{array}{l}\text { Critical Studies Media } \\
\text { Communications }\end{array}$ & 3 & 0 & 1 & 1 & 0 & 0 & 0 & 0 & 0 & 0 & 0 & 0 & 0 & 5 & 2.4 & 110 & 4.6 \\
\hline Cultural Studies & 9 & 3 & 4 & 5 & 0 & 0 & 0 & 0 & 0 & 0 & 0 & 1 & 1 & 23 & 11.0 & 171 & 13.5 \\
\hline Discourse studies & 1 & 0 & 0 & 0 & 0 & 0 & 0 & 0 & 0 & 0 & 0 & 0 & 0 & 1 & 0.5 & 150 & 0.7 \\
\hline Discourse and Society & 3 & 0 & 1 & 0 & 0 & 0 & 0 & 0 & 0 & 0 & 0 & 0 & 0 & 4 & 1.9 & 124 & 3.2 \\
\hline $\begin{array}{l}\text { Environmental Communi- } \\
\text { cation }\end{array}$ & 0 & 1 & 0 & 0 & 0 & 0 & 0 & 0 & 0 & 0 & 0 & 0 & 0 & 1 & 0.5 & 80 & 1.3 \\
\hline $\begin{array}{l}\text { European Journal of } \\
\text { Communication }\end{array}$ & 0 & 0 & 1 & 1 & 0 & 0 & 0 & 0 & 0 & 0 & 0 & 0 & 0 & 2 & 1.0 & 90 & 2.2 \\
\hline $\begin{array}{l}\text { European Journal of Cul- } \\
\text { tural Studies }\end{array}$ & 5 & 0 & 0 & 0 & 0 & 0 & 0 & 0 & 0 & 0 & 0 & 0 & 0 & 5 & 2.4 & 114 & 4.4 \\
\hline $\begin{array}{l}\text { Transactions on Profes- } \\
\text { sional Communication }\end{array}$ & 2 & 0 & 0 & 0 & 0 & 0 & 0 & 0 & 0 & 0 & 0 & 0 & 0 & 2 & 1.0 & 116 & 1.7 \\
\hline $\begin{array}{l}\text { Information Communica- } \\
\text { tion \& Society }\end{array}$ & 6 & 0 & 0 & 0 & 0 & 0 & 0 & 0 & 0 & 0 & 0 & 0 & 0 & 6 & 2.9 & 195 & 3.1 \\
\hline Interasia Cultural Studies & 9 & 1 & 2 & 1 & 1 & 0 & 0 & 0 & 0 & 0 & 0 & 0 & 0 & 14 & 6.7 & 144 & 9.7 \\
\hline $\begin{array}{l}\text { International Journal of } \\
\text { Conflict Management }\end{array}$ & 2 & 0 & 0 & 0 & 0 & 0 & 0 & 0 & 0 & 0 & 0 & 0 & 0 & 2 & 1.0 & 88 & 2.3 \\
\hline $\begin{array}{l}\text { International Journal of } \\
\text { Press/Politics }\end{array}$ & 1 & 0 & $U$ & 0 & 0 & 0 & 0 & 0 & 0 & 0 & 0 & 0 & 0 & 1 & 0.5 & 110 & 0.9 \\
\hline
\end{tabular}




\begin{tabular}{|c|c|c|c|c|c|c|c|c|c|c|c|c|c|c|c|c|c|}
\hline \begin{tabular}{|l|} 
International Journal of \\
Public Opinion research
\end{tabular} & 0 & 0 & 1 & 0 & 0 & 0 & 0 & 0 & 0 & 0 & 0 & 0 & 0 & 1 & 0.5 & 71 & 1.4 \\
\hline Journal of Communication & 1 & 1 & 0 & 0 & 0 & 0 & 0 & 0 & 0 & 0 & 0 & 0 & 0 & 2 & 1.0 & 163 & 1. \\
\hline $\begin{array}{l}\text { Journal of Computer- } \\
\text { Mediated Communication }\end{array}$ & 1 & 0 & 0 & 0 & 0 & 0 & 0 & 0 & 0 & 0 & 0 & 0 & 0 & 1 & 0.5 & 184 & 0 \\
\hline $\mathrm{J}$ of Mass Media Ethics & 2 & 0 & 0 & 0 & 0 & 0 & 0 & 0 & 0 & 0 & 0 & 0 & 0 & 2 & 1.0 & 82 & 2.8 \\
\hline Journalism Studies & 4 & 1 & 1 & 0 & 0 & 0 & 0 & 0 & 0 & 0 & 0 & 0 & 0 & 6 & 2.9 & 219 & 2.7 \\
\hline on & 1 & 0 & 0 & 0 & 1 & 0 & 0 & 0 & 0 & 0 & 0 & 0 & 0 & 2 & 1.0 & 88 & 2. \\
\hline $\begin{array}{l}\text { Man } \\
\text { tion }\end{array}$ & 2 & 2 & 0 & 0 & 0 & 0 & 0 & 0 & 0 & 0 & 0 & 0 & 0 & 4 & 1.9 & 76 & 5. \\
\hline $\begin{array}{l}\text { Mass Comr } \\
\text { Society }\end{array}$ & 1 & 0 & 0 & 0 & 0 & 0 & 0 & 0 & 0 & 0 & 0 & 0 & 0 & 1 & 0.5 & 107 & 0. \\
\hline Media Culture \& Society & 4 & 1 & 1 & 0 & 0 & 0 & 1 & 0 & 0 & 0 & 0 & 0 & 0 & 7 & 3.3 & 210 & 3.3 \\
\hline New Media and Society & 3 & 0 & 0 & 0 & 0 & 0 & 0 & 0 & 0 & 0 & 0 & 0 & 0 & 3 & 1.4 & 231 & 1.3 \\
\hline Public Culture & 3 & 2 & 1 & 0 & 0 & 0 & 0 & 0 & 0 & 0 & 0 & 0 & 0 & 6 & 2.9 & 123 & 4.9 \\
\hline PR review & 2 & 0 & 0 & 0 & 0 & 0 & 0 & 0 & 0 & 0 & 0 & 0 & 0 & 2 & 1.0 & 150 & 1.3 \\
\hline Quarterly J of Speech & 1 & 0 & 1 & 0 & 0 & 0 & 1 & 0 & 0 & 0 & 0 & 0 & 0 & 3 & 1.4 & 85 & 3.5 \\
\hline Rhetoric Society Quarterly & 5 & 1 & 2 & 0 & 0 & 0 & 0 & 0 & 0 & 0 & 0 & 0 & 0 & 8 & 3.8 & 80 & 10.0 \\
\hline Science Communication & 1 & 0 & 0 & 0 & 0 & 0 & 0 & 0 & 0 & 0 & 0 & 0 & 0 & 1 & 0.5 & 92 & 1.1 \\
\hline Screen & 2 & 0 & 0 & 0 & 0 & 0 & 0 & 0 & 0 & 0 & 0 & 0 & 0 & 2 & 1.0 & 74 & 2 \\
\hline $\begin{array}{l}\text { Telecommunications Poli- } \\
\text { cy }\end{array}$ & 2 & 0 & 0 & 0 & 0 & 0 & 0 & 0 & 0 & 0 & 0 & 0 & 0 & 2 & 1.0 & 258 & 0. \\
\hline Theory Culture \& Society & 29 & 9 & 9 & 1 & 1 & 2 & 0 & 1 & 3 & 1 & 0 & 0 & 0 & 56 & 26.7 & 247 & 22.7 \\
\hline Television and New Media & 2 & 0 & 1 & 0 & 0 & 0 & 0 & 0 & 0 & 0 & 0 & 0 & 0 & 3 & 1.4 & 100 & 3.7 \\
\hline Visual Communication & 2 & 0 & 0 & 0 & 0 & 0 & 0 & 0 & 0 & 0 & 0 & 0 & 0 & 2 & 1.0 & 82 & 2.4 \\
\hline Written Communication & 1 & 0 & 1 & 0 & 0 & 0 & 0 & 0 & 0 & 0 & 0 & 0 & 0 & 2 & 1.0 & 68 & 2. \\
\hline Total & $\mid 121$ & 31 & 31 & 12 & 3 & 2 & 2 & 1 & 3 & 1 & 1 & 1 & 1 & 210 & 100.0 & 4979 & \\
\hline$\%$ & $\mid 57.6$ & 14.8 & 14.8 & 5.7 & 1.4 & 1.01 & $1.0 \mid$ & 0.5 & $1.4 \mathrm{C}$ & 0.5 & 0.50 & 0.5 & 0.5 & 100.0 & & & \\
\hline
\end{tabular}

Table 3: Distribution of the use of Marx's name in the main text of the articles

\footnotetext{
a Provides a discussion using Marx's ideas

${ }^{b}$ The whole article is dedicated to Marx/Marxism, Marxist view's, Marxist analysis or an evaluation of Marx or Marxism

${ }^{c}$ Uses Marx to provide a Marxist analysis of class, exploitation, media and the like

${ }^{d}$ The whole article uses a Marxist analysis of a topic

e The whole article is dedicated to discuss the view of a person on Marx and Marxism

${ }^{f}$ The whole article is about autonomous Marxism: the inadequacy of it or as alternative to classical Marxizm

${ }^{g}$ The whole article uses Marx and Marxism throughout the article while discussing a marxist intellectual

${ }^{\mathrm{h}}$ 'The whole article uses Marx's ideas for the author's (Grossberg) revised theory of conjunctural analysis

i The whole article is a decolonialist invalidation and accusation of Marx without presenting a reading of Marx
}

\section{Using Marx's Writings}

Of 450 articles that mention Marx or Marxism at least once, $85.1 \%$ do not use any writing of Marx in their references, while $4.0 \%$ use The Capital, 1.5\% The German Ideology, 1.1\% The Communist Manifesto. Only seven articles use 2, three articles use 3, and two articles use more than 3 sources from Marx.

Such findings indicate the existence of an extremely low interest in reading Marx. It also shows that those who write something about Marx do not use Marx's own writings, but either secondary sources that support their stance or their own personal ideas of what Marx said, which implies the low and/or wrong knowledge communication scholars have of Marx's works.

While searching for sources, I also realized that there was a drastic drop in the use of Marx and Marxism since the beginning of 1 the 990 s (especially since 1992) in these journals. 


\section{Nature of the Use of Marx's Name}

The nature of the use of Marx's name differs widely, ranging from a very strong anti-Marxist position to a Marxist evaluation of a topic.

Over half $(50.9 \%)$ of the 210 articles that use Marx's name, use it merely as part of an explanation with no evaluative or normative statement. Most of these articles mention Marx's name once or twice. The rest of the articles has various orientations toward Marx (figure 2):

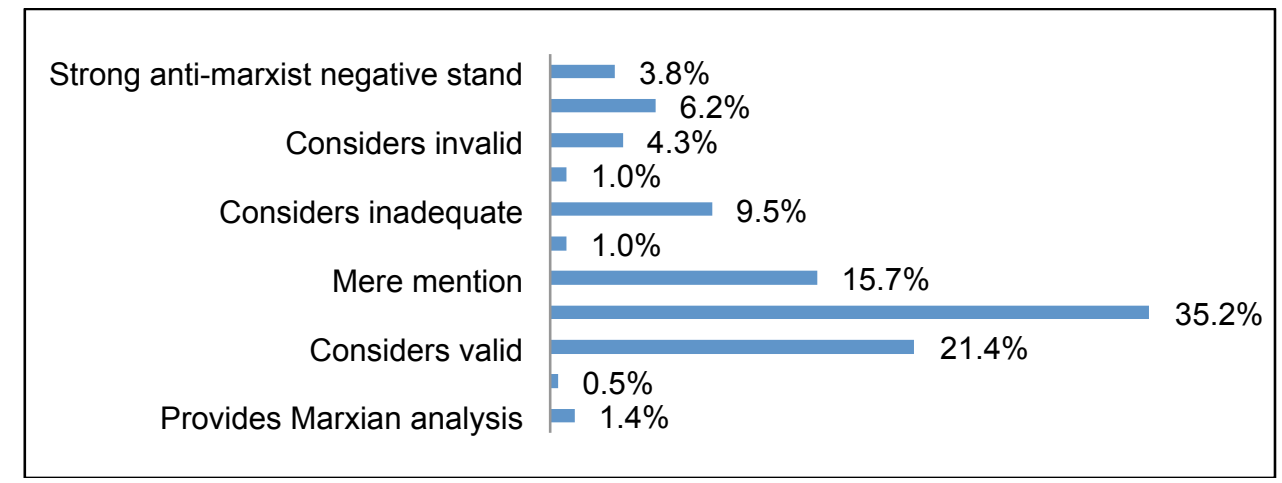

Figure 2: Distribution of the evaluation of Marx in the analysed articles

Negative stands (25.8\%):

- $3.8 \%$ provide strong anti-Marx statements or negative evaluations (e.g., totalitarian, enemy of democracy, crude analysis; Eurocentric, utopian, pseudo-scientific).

- $10.5 \%$ provide a negative evaluation and consider Marx's ideas invalid (Marx's ideas about the base and superstructure; class; class conflict/struggle; ruling class and ruling ideas; the public sphere; theory of value; revolutionary change; the concept of labour; ideology; commodity fetishism; resistance).

- $1.0 \%$ consider Marx's ideas partially invalid.

- $10.5 \%$ consider Marx's thinking as waning and inadequate.

Positive stand/evaluation (23.3\%)

- $21.4 \%$ use one or more concepts or theoretical approaches of Marx for explanation or analysis (for instance, men make history; aim is not only to understand, but to change society; the interplay of symbolic and material forces; creativity; humanism; labour; myth; ideology; slavery; technology; false consciousness; progress; proletariat; Asian modes of production; formal political equality; commodity, commodity production; fetishism; utopias; labour; class and exploitation; capitalist crisis; class struggle; press; freedom; historical materialism as basis of cultural studies; circulation and consumption; primitive accumulation).

- $1.4 \%$ provide some kind of Marxist analysis (the Internet, an issue, a historical explanation).

These findings are very interesting because most of the negative evaluations and invalidations do not have mainstream orientations as background.

\subsection{Theoretical Orientations}

The sample for the analysis of theoretical orientations of communication journals included 385 articles out of a total of 10104. The study found that the 385 articles used 150 theoretical approaches. This finding supports the routine complaints of communication scholars that there are multitudes of theoretical orientations in communications. It is true that there are many theoretical approaches in communication, however, most of them, including sociology-based, qualitative, structuralfunctionalist ones, are based on social psychology.

$60.8 \%$ of all studies have study designs with no theoretical reasoning, rationale or discussion at all (table 4). Similarly, Potter, Cooper and Dupagne (1993) found that $91.9 \%$ of their analysed articles had no theoretical foundations. A study by Potter and Riddle (2007) found the same result for $57.1 \%$. The result reported in Riffe and Freitag's study (1997) was also high: $72.4 \%$. Kamhawi and Weaver (2003) found no theory in $69.5 \%$ of the articles in their analysed sample. 


\begin{tabular}{|c|c|c|}
\hline Theoretical Content & $\mathbf{N}$ & $\%$ \\
\hline $\begin{array}{l}\text { Few theories/models are presented, but no theoretical framework is established for } \\
\text { the study }\end{array}$ & 7 & 1.8 \\
\hline No theory with theoretical reasoning/rationale/discussion is presented at all & 219 & 56.9 \\
\hline $\begin{array}{l}\text { A ready theoretical approach was used, but no theoretical framework was established } \\
\text { for the studying questions/hypotheses }\end{array}$ & 8 & 2.1 \\
\hline A theoretical structure exists to a varying degree & 151 & 39.2 \\
\hline Total & 385 & 100.0 \\
\hline
\end{tabular}

Table 4: Distribution of the existence of a theoretical structure

Studies with theoretical structures that have a varying degree of proper theoretical construction make up only $39.2 \%$. Indeed, there is a very limited number of studies that uses a theoretical framework for their study, provide theoretical assumptions or extract research questions or hypotheses, and construct conclusions based on proper synthesis of their study findings, theoretical rationale and accumulated knowledge.

All these results show that there is a widespread tendency that researchers do not use a theoretical reasoning in their design and that Media and Communication Studies lack epistemological validity beyond providing information for control purposes.

Although the majority of the articles in this study does not have a specified theoretical framework, I found that $56 \%$ of all articles use mainstream approaches that are mostly based on socialpsychology, followed by $9.8 \%$ the employ neo-liberal pluralism, $9.9 \%$ that are focused on various types of critical approaches, $8.6 \%$ that use post-structuralism. $4.7 \%$ are liberal-democrat in orientation, $\% 3.9 \%$ constructionist, $2.6 \%$ post-modern, $2.6 \%$ have no-theoretical structure at all (they emphasize the functionality of a tool, procedure or application), $0.5 \%$ are post-colonial, $0.3 \%$ postpositivist, $0.8 \%$ neo-Marxist, and $0.5 \%$ critical political economy.

The problems of macro-level power relations, material and immaterial interests of organized power structures are not present in almost all theoretical approaches and study designs. Power and power relations are typically conceptualized (1) in terms of freedom of individual choices (by dominant approaches) or (2) in terms of "the death of the author" (the powerlessness of producing and disseminating industrial structures) in the face of an empowered individual audience that deconstructs and re-constructs everything according to his/her own free will, or (3) in terms of the popularized identity politics which are set against the focus on class identity, the mode and relations of production.

It seems like the term "Marxist political economy" is a cursed word: I did not see any article using the term. However, those approaches with a "post" prefix show interest in using the terms political economy and economic determinism interchangeably. They mostly advocate the end of political economy, class and ideology, and claim that all of these categories belong to the past. Political economy or critical political economy is used in a few articles.

\subsection{The Studied Topics}

The sample for the analysis of communication topics included 1386 articles of a total of 10104 .

The topics that were identified in the analysis are presented under three categories: topics related to technologically mediated communication (823; $59.4 \%$ ), technologically unmediated communication $(236 ; 17.0 \%)$, and others that include anything that falls outside the first two groups $(327 ; 23.6 \%)$.

The studies about the mediated communication have a rich variety, but $49.8 \%$ of all articles focus on mass communication related issues (table 5).

\begin{tabular}{|l|r|r|}
\hline Issues & $\mathbf{N}$ & $\mathbf{\%}$ \\
\hline Access & 10 & 1.2 \\
\hline Accountability & 2 & 0.2 \\
\hline Accuracy & 1 & 0.1 \\
\hline Advertising, marketing & 24 & 2.9 \\
\hline Attitude, perception and behaviour of media professionals & 8 & 1.0 \\
\hline Audience reception, intertextuality, interpretation, evaluation, construction & 6 & 0.7 \\
\hline Content: Media product analysis & 31 & 3.8 \\
\hline Conversation (technologically mediated); managing impartiality & 1 & 0.1 \\
\hline Culture, mediated multiculturalism; intercultural relations, cultural struggle & 7 & 0.9 \\
\hline Development/history: media, communication education, & 23 & 2.8 \\
\hline
\end{tabular}




\begin{tabular}{|c|c|c|}
\hline Discourse (technologically mediated) & 17 & 2.1 \\
\hline $\begin{array}{l}\text { Effect: Attitude, perception, behaviour, motivation, commitment, preferences, beliefs, partic- } \\
\text { ipation, trust, emotions and personality of individuals }\end{array}$ & 66 & 8.0 \\
\hline Effects in general & 135 & 16.4 \\
\hline Effectiveness & 11 & 1.3 \\
\hline Environment & 3 & 0.4 \\
\hline Ethics & 8 & 1.0 \\
\hline Media analysis & 21 & 2.6 \\
\hline Identity and identity politics & 14 & 1.7 \\
\hline Mediated interaction (parasocial and human-robot) & 16 & 1.9 \\
\hline Internet, web, online games, use of social media & 29 & 3.5 \\
\hline Language use & 4 & 0.5 \\
\hline Policy, politics, law, regulation, control and freedom of communication, censorship & 57 & 6.9 \\
\hline Media constructions/meaning & 14 & 1.7 \\
\hline Media coverage/portrayal/framing, representation & 77 & 9.4 \\
\hline Media education communication education & 1 & 0.1 \\
\hline Media economics, industry, industrial relations & 20 & 2.4 \\
\hline Method: model, measurement, data analysis & 35 & 4.3 \\
\hline Production mode/relations (media, music industry) & 2 & 0.2 \\
\hline Product design & 2 & 0.2 \\
\hline Professional culture, values, practices, production & 34 & 4.1 \\
\hline Research/study & 15 & 1.8 \\
\hline Role/function of media & 44 & 5.3 \\
\hline Space, audience viewing space & 5 & 0.6 \\
\hline Surveillance & 3 & 0.4 \\
\hline Source credibility & 1 & 0.1 \\
\hline System/structure of media (mainstream) & 5 & 0.6 \\
\hline Technology & 9 & 1.1 \\
\hline $\begin{array}{l}\text { Theory (includes theories in organizational communication, media, public relations, advertis- } \\
\text { ing and cultural studies) }\end{array}$ & 47 & 5.7 \\
\hline Use of media (nature/character of use) & 15 & 1.8 \\
\hline Total & 823 & 100.0 \\
\hline
\end{tabular}

Table 5: Distribution of topics in technologically mediated communication

The classical effect studies in mass communication still reign over others and have been extended to the new media (especially to computer-mediated communication). The concentration on effects and an expanding interests in media effects has been documented in many studies, like the one conducted by Shaw, Ham and Knott (2000), who provide a concise evaluation of the theories and the effect (and other) interests in communication studies and indicate that "we live in a post-mass media age, but studies of the effects of mass media remain our strongest research tradition" ( $p$. 72).

The most common types of studies topics are effect related issues dealing with attitude, perception, behaviour, motivation, commitment, preferences, beliefs, participation, trust, emotions and personality of individuals and media $(24.4 \%)$. Studies focusing on media content, portrayal and representation represent $14.9 \%$. Only $3.5 \%$ of the studies focus on Internet-related issues (web, online games, use of social media).

Conversely, there is little interest in studying critical issues relating to industrial production, distribution and relations and working conditions and relations at the workplace. Mostly liberalpluralists and those who use theories with a "post"-prefix are interested in media portrayal and representation beyond effect issues. Only $2.4 \%$ of 823 articles study one or more aspects of the industry (media economics, industry, industrial relations). However, only 3 of them use the Marxist approach (two critical political economy and one the neo-Marxist critical school). Such findings indicate that very few academicians are interested in studying issues related to the structure or nature of the communication industry.

Studies on technologically unmediated communication concern the rich variety of unmediated communication. However over one third of them $(36.9 \%)$ deals with issues in interpersonal communication, technologically unmediated (conversation; word of mouth talk), interpersonal communication or technologically unmediated speech/oral communication. Organizational communication follows with $15.5 \%$. Studies on various issues of self-communication occupy $10.2 \%$ (table 6 ). None 
of these studies investigates issues related to individual and/or interpersonal manifestations of the human condition in the economic, cultural and political organizations. They are mostly interested in (a) knowing psychological and behavioural/preferential characteristics of individuals, (b) the way individuals initiate and maintain personal relations, solve conflicts and end relations, and (c) ways and means for increasing employee's motivation, involvement and participation in their own exploitation at work.

\begin{tabular}{|c|c|c|}
\hline Issues & $\mathbf{N}$ & $\%$ \\
\hline $\begin{array}{l}\text { Attitude, perception, behaviour, motivation, commitment, preferences, beliefs, participation, } \\
\text { trust, emotions and personality of individuals }\end{array}$ & 37 & 15.7 \\
\hline Conflict resolution/mediation, communicative strategy, risk reduction & 3 & 1.3 \\
\hline Conversation, action, turn taking & 3 & 1.3 \\
\hline Culture & 2 & 0.8 \\
\hline Decision making & 3 & 1.3 \\
\hline Discourse & 5 & 2.1 \\
\hline Education & 1 & 0.4 \\
\hline Effect & 28 & 11.9 \\
\hline Effectiveness & 8 & 3.4 \\
\hline Face management, relation maintenance, self-disclosure & 7 & 3.0 \\
\hline Identity and identity politics & 18 & 7.6 \\
\hline $\begin{array}{l}\text { Individual's ability of thinking, memory, framing thoughts, expression, speaking, compre- } \\
\text { hension }\end{array}$ & 7 & 3.0 \\
\hline Interaction: agency, conversation, listening, skills, natural occurrence & 18 & 7.6 \\
\hline Intervention for children in the family environment & 1 & 0.4 \\
\hline Language & 7 & 3.0 \\
\hline Language learning & 2 & 0.8 \\
\hline Language use & 11 & 4.7 \\
\hline Method: model, measurement, data analysis & 12 & 5.1 \\
\hline Narration: narrative, individual, life stories, refuge camps & 10 & 4.2 \\
\hline Policy, politics, law, regulation, control and freedom of communication, censorship & 1 & 0.4 \\
\hline Product (list, description) & 1 & 0.4 \\
\hline Professionalism, professional practices & 4 & 1.7 \\
\hline Racism, race talk & 2 & 0.8 \\
\hline Reader's evaluation & 1 & 0.4 \\
\hline Research/study & 4 & 1.7 \\
\hline Rhetoric & 3 & 1.3 \\
\hline Role of communication, talk, leadership & 4 & 1.7 \\
\hline Situational and psychological factors of an individual's behaviour, speech & 1 & 0.4 \\
\hline Speech & 1 & 0.4 \\
\hline Surveillance & 1 & 0.4 \\
\hline Technology (assistive, science, linguistic devices) & 1 & 0.4 \\
\hline Theory & 28 & 11.9 \\
\hline Vernacular science knowledge & 1 & 0.4 \\
\hline Total & 236 & 100.0 \\
\hline
\end{tabular}

Table 6: Distribution of issues in technologically unmediated communication

Studies on other issues are concentrated on a multitude of issues (table 7). Here too, the majority of issues are related to the effect, individuals' dispositions and behaviour. Engaging with a critical issue or conducting a critical analysis of an issue is at a minimum level.

\begin{tabular}{|c|c|c|}
\hline Issues & $\mathbf{N}$ & $\%$ \\
\hline $\begin{array}{l}\text { Attitude, perception, behaviour, cognition, motivation, commitment, preferences, be- } \\
\text { liefs, opinions, participation, trust, emotions, affect and personality of individuals }\end{array}$ & 32 & 9.8 \\
\hline Auditory systems & 1 & 0.3 \\
\hline Collaboration and creativity, democracy, diversity & 1 & 0.3 \\
\hline Conversion: religious & 1 & 0.3 \\
\hline Culture, intercultural competence, transcultural literacy, art & 12 & 3.7 \\
\hline Decision making & 1 & 0.3 \\
\hline Development of a discipline & 1 & 0.3 \\
\hline Discourse & 1 & 0.3 \\
\hline Dispute resolution, organizations & 9 & 2.8 \\
\hline Economics, human capital (drug testing on humans) & 1 & 0.3 \\
\hline Effect & 26 & 8.0 \\
\hline
\end{tabular}




\begin{tabular}{|c|c|c|}
\hline Effectiveness & 5 & 1.5 \\
\hline Environment: protection & 1 & 0.3 \\
\hline Ethics & 2 & 0.6 \\
\hline Health: tanning and skin cancer & 1 & 0.3 \\
\hline History, civil war; wine production & 2 & 0.6 \\
\hline Identity and identity politics & 19 & 5.8 \\
\hline Ideology, artefactual ideologies & 2 & 0.6 \\
\hline Individual's adaptation to living environment & 1 & 0.3 \\
\hline Individual's knowledge, memory, framing thoughts, expression & 7 & 2.1 \\
\hline Individual's physical and mental health & 1 & 0.3 \\
\hline Interaction: cooperation, cognitive processing, social relationship & 19 & 5.8 \\
\hline Intervention for children in the family environment & 1 & 0.3 \\
\hline Language learning, impairment & 9 & 2.8 \\
\hline Language use, reading, learning & 5 & 1.5 \\
\hline Language, type, semantics, history, development, structure, use & 15 & 4.6 \\
\hline Leadership, multicultural & 1 & 0.3 \\
\hline Method, learning, writing, training & 7 & 2.1 \\
\hline Method: book design, explanation of a therapy & 2 & 0.6 \\
\hline Method: model, measurement & 22 & 6.7 \\
\hline Narration: transcultural narrative, trade, therapy & 3 & 0.9 \\
\hline Nationalism, racialization, sexism, weapons promotion, & 4 & 1.5 \\
\hline Organizational management, authority, cooperation, knowledge construction, change & 4 & 1.5 \\
\hline Policy, politics, torture, participation, biopolitics, human rights, privacy & 30 & 9.1 \\
\hline Pretend play: enacting hierarchical form of social organization & 1 & 0.3 \\
\hline Public understanding of science & 1 & 0.3 \\
\hline Research/study & 14 & 4.3 \\
\hline Rhetoric: ethnicity, presidential & 2 & 0.6 \\
\hline Simulation of nature: zoos & 1 & 0.3 \\
\hline Space and time: global space, regionalization & 3 & 0.9 \\
\hline Speech problems, symptoms, treatment, therapy, impairment, articulation & 12 & 3.7 \\
\hline Surveillance, monitoring & 1 & 0.3 \\
\hline Technology and technology use: imaging tools, devices, web applications & 6 & 1.8 \\
\hline Theory (terrorism, colonialism, modernity, reality & 34 & 10.4 \\
\hline Violence: acid violence & 1 & 0.3 \\
\hline Voting & 1 & 0.3 \\
\hline Total & 327 & 100.0 \\
\hline
\end{tabular}

Table 7: Distribution of other issues

Not only the present study but also almost all related studies found that there are vast varieties of issues, theoretical approaches and methods. According to Potter and Riddle (2007, 8), a wide range of effects and methods, and little overlap in research work "could make it difficult for scholars to share definitions of key terms and a 'big picture' understanding of the overall field". Potter's concern would be a valid one if the primary interest and concern of researchers were to understand the overall field.

All the findings clearly indicate that dominant orientations of scholarly interest in communication research are based on the need of the industrial and institutional structure to know more about individuals and to assess media effects. The obvious implication of such orientations validates Marx's statement about the relationship between the ruling class and ideas in class societies. Under the prevailing scholarly interests and the factors that lead and feed the researchers/academicians, it becomes ridiculous, illogical and dysfunctional to ask questions like (a) why many scholars do not study the attitudes, perceptions, values, feelings, psychological health, racism, sexism, militarism and discourse of individuals belonging to the ruling class, (b) do not analyze the effect of their psychological disposition on the nature of production and distribution, the working conditions, minimum wage policies and miserable human and environmental conditions, and (c) do not suggest, at the end of the study, that the ruling class and their highly educated managerial cadres (not the people) should be educated, should go through sensitivity and empathy training, and should feel the feelings of being powerless, exploited, abused and misused.

The theories and study topics that have dominant communication studies in the last 60 years are still dominant. Some formerly marginal topics (especially hermeneutics, semiotics, constructivism and structuralism) are supplementary and fashionable alternatives now. They are the preferred theoretical approaches not because they have better explanatory power and epistemological and methodological validity, but because they are integrated into the global and glocal marketing and 
business interests, and because they are extremely functional for the mind and behaviour management, and thus, for the ruling interest of our times.

Most articles that refer to Marxism/Marx provide handy statements on the classical, economic determinist, reductionist, mechanistic or orthodox Marxisms, and make cliché judgments about Marxist reflectivity, historicism, Euro-centricism, fundamentalism, class bias, overdetermination, grand narrative and the like.

\section{Marx's Place in Understanding Communication}

A message, a word, talking, conversation, a communicative action or sending and receiving messages are not communication. We should not confuse communication with tools, means, expressions, representations, verbal and nonverbal actions or content of communication. Communication is one of the necessary conditions of biological and social existence of human beings: We could not produce and reproduce ourselves physically, psychologically, socially, economically or any other ways if we were unable to communicate. No communication means dead people, a dead society and a dead world. Nothing humanly is possible without communication. Communication, means of communication, language, symbols and the like do not exist individually; we do whatever we do in relation to each other and ourselves through the ways and means of material and mental production and social relations.

Marx takes a central place in understanding the importance, nature and the study of communication because he provided us with the most meaningful ways of knowing about anything related to communication. We can find the varying influence of his theoretical and methodological orientation in all alternative and liberal-democratic studies of communication. The most significant and enduring communication literature is based on approaches influenced by Marx's understanding of every aspect of human life. Marx is not part of the supportive mechanisms of dominant ways of reproducing the ruling interests, structures and relations. That is why it is the normalized part of the abnormal modes of reproduction of domination to ignore, exclude, chastise or downgrade Marx in Media and Communication Studies. Yet, Marx always finds his place in communication in the praxis of demystifying the mystified, the analysis of and struggle against the unjust and oppressive modes and relations of production, including intellectual and professional relations and practices in communications. Marx's humane interest, theory and method are starting points for or continuation of meaningful communication inquiry. However, we know that Marx also provided explanations concerning communication.

Findings in a specific organized time and organized place and/or organized relations can or cannot be valid in another time, place or relations, because of the changing conditions of theoretical reasoning/construction. Changes in conditions are not the necessary or sufficient condition for revisions or invalidation of a theory. A theory or a part of a theory looses its validity if the methodological structure of inquiry and/or the theoretical reasoning is unable to provide valid explanations for new, varying or changing conditions. Marx's theory is not a theory of maintenance, equilibrium, balance and justification of any organized mode and relations. It is a theory based on the study and explanation of the formation, maintenance and change. His theory and method should occupy a central place in understanding communication, because understanding communication requires understanding human and organized life beyond finding or forging justifications for it.

Marx's approach in communication mainly focuses on (1) the study of the nature of material production (material modes and relations) of communication (organization and practices of reproduction of structured-selves and communication products and thus reproduction of the human condition), (2) the study of immaterial production (immaterial modes and relations) of communication (production, dissemination and use of ideas, feelings, sensitivities, beliefs, information, knowledge, ignorance as knowledge), and (3) interrelations in and between the material and immaterial production of communication, but not in terms of reproducing the propagandist ignorance of the question of (a) what comes first (egg or chicken; base or superstructure), (b) overdetermination, (c) the death of the producer, and (d) the empowered individuals who deconstruct and reconstruct meanings according to their free will and wage struggle in front of the television and/or in the virtual world of cyberspace.

\subsection{Marx on Communication}

\subsubsection{The Concept of Communication: What is Communication for Marx?}

We were educated in such a way that we have to know the definition, like the definition of communication. We cannot define communication with a single sentence. Communication (even an apple) 
cannot be correctly defined by a single or a few common properties. Furthermore, the answer to the question of what communication is does not come in five choices and one right answer. A scientific definition requires a kind of detailed explanation that includes properties/indicators of communication in general and a historically specific context so that we can learn what it is, and also provides exclusionary explanations so that we can learn what it is not. There are many definitions of communication, but none of them explains what communication is, because they are definitions focusing on the mechanics/processes of encoding and decoding, the observable interactions like sending and receiving messages, exchanging ideas, elements, functions, roles, goals or structures. Nobody communicates in order to send or receive a message or to create, construct, consume or deconstruct meanings. Communicative action, message, writing, saying something, reading a book or watching television do not constitute communication. Verbal expressions or any kind of mental or relational manifestations are also not "communication".

Marx does not define communication; however, we find very important explanations about communication in his writings. The following itemized presentation of Marx's understanding of communication invalidates (1) the claims that Marx did not deal with communication, (2) the assessment that Marx only talked about means of communication and (3) the evaluations that Marx reduced communication to "transportation".

I extracted phrases or sentences from Marx's writings and provided brief explanations:

- "Cheap and quick communications" (Marx 1846): Existence of two indicators of two groups of the qualitative nature of communication.

- "Is the Iliad possible at all when the printing press and even printing machines exist? Is it not inevitable that with the emergence of the press bar the singing and the telling and the muse cease, that is the conditions necessary for epic poetry disappear?" (Marx 1857a): historically accumulated and determined nature of communication and production of communication.

- "Conditions of Production and Communication; Political Forms and Forms of Cognition in Relation to the Conditions of Production and Communication" (Marx 1857a): These are the titles in the main text. These titles indicate that Marx is interested in conditions of communication, and the relationship of communication to political structures and cognition.

- "The relations between productive power and the conditions of communication" (Marx 1857a): This self-exploratory phrase indicates the importance of the conditions of communication in influencing the productive power.

- $\quad$ "there are certain independent branches of industry in which the product of the productive process is not a new material product, is not a commodity. Among these only the communications industry, whether engaged in transportation proper, of goods and passengers, or in the mere transmission of communications, letters, telegrams, etc., is economically important" (Marx 1885, chapter 1, 17): Importance of the communication industry.

- "interfering with the British communications with Kurnaul and Meerut" (Marx 1857): Control of communication.

- "English line of communication between Agra and Delhi" (Marx 1857): Communication networks in the colonies.

- "The Morning Chronicle, in its fourth edition, communicated a telegraphic despatch" (Marx 1853): Communicating by sending a dispatch/content using the telegraph.

- "The limited commerce and the scanty communication between the individual towns" (Marx 1846): Quantitative nature of Communication and its outcome.

- "The possibility of commercial communications transcending the immediate neighbourhood, a possibility, the realisation of which depended on the existing means of communication" (Marx 1846): Acknowledging the existence of various forms of communication, like commercial communications; implying that communication is done via means of communication; emphasizing the determining role of means of communication.

- $\quad$ "[...] public word in all its forms - in spoken form, in written form, and in printed form, print not yet censored as well as that already censored, [...] local press. (Marx 1843g): Various forms of communication.

- "Established means of communication" (Marx 1846): Role of established means of communication.

- "Influence of the means of communication" (Marx 1857a): influence/outcome of communication.

- "Louis Napoleon has communicated a similar message to his Senate and Corps Législatif". (1854): Communicating a message. 
- "Centralisation of the means of communication and transport in the hands of the State" (Marx 1848a): Monopoly in communication; political economy of communication.

- "This market has given an immense development to commerce, to navigation, to communication by land" (Marx 1848a): Development of communication and market influence on it.

- "The bourgeoisie, by the rapid improvement of all instruments of production, by the immensely facilitated means of communication, draws all, even the most barbarian, nations into civilisation" (Marx 1848a): Role of development of the means of communication.

- "This union is helped on by the improved means of communication that are created by modern industry" (Marx 1848a): Role of communication in society.

- "An organised system of machines, to which motion is communicated by the transmitting mechanism from a central automaton" (Marx 1867, chapter 15, 3): Technology, organizational communication; machine-to-machine communication.

- "The means of communication and transport were so utterly inadequate to the productive requirements of the manufacturing period" (Marx 1867): Influence of the condition of communication in production.

- "The means of communication and transport became gradually adapted to the modes of production of mechanical industry" (Marx 1867): Political economy of communication; industrial relations, technological control.

- "The improved means of transport and communication furnish the weapons for conquering foreign markets" (Marx 1867): Role of communication in colonisation; international political economy of communication; war communication.

- "The development of ocean navigation and of the means of communication generally, has swept away the technical basis on which season-work was really supported" (Marx 1867): Role of communication in industrial development and relations, work force and trade.

- "At a given stage of development of technology and of the means of communication, the discovery of new territories containing gold or silver plays an important role" (Marx 1859): Role of communication in development, colonization.

- "It is clear that the progress of social production in general has, on the one hand, the effect of evening out differences arising from location as a cause of ground-rent, by creating local markets and improving locations by establishing communication and transportation facilities" (Marx 1863-1883): Role of communication facilities; political economy of communication.

- "Continental politicians, who imagine that in the London press they possess a thermometer for the temper of the English people, inevitably draw false conclusions at the present moment" (Marx 1861): In this article, Marx focuses on political communication; the relationship among media, politicians and people; the role of the press in war; close material relations between top media professionals and ruling forces; the control of the press by politicians and corporate structures; the ownership of the press; interests that the London press upholds.

The short examples above also indicate that what Marx says in these short phrases is a lot more meaningful than, for instance, (a) millions of "effect analyses" that provide nothing more than distributional and relational information to serve the interests of marketing and/or political control and (b) some reception analyses that do talk about the nature of reception just like active audience theorists without using functionalist terminology and without analyzing receptors/individuals.

Marx said a lot more.

\subsubsection{Location and Function/Role of Communication in Society and Social Development}

Marx locates communication in every moment of the material and immaterial production of life. The explanations that Marx provides on ideas, the press, writing, means and roles of communication clearly indicate that communication for Marx is an essential factor for the existence of the societal production of life (that includes distribution, circulation and consumption). In addition to the ideas that are presented in the other sections of this article, the following explanation of Marx implies not only the relational aspect and role of communication, but also the necessity of communication in every sphere of social life:

"so soon as it (linen) comes into communication with another commodity, the coat. Only it betrays its thoughts in that language with which alone it is familiar, the language of commodities. In order to tell us that its own value is created by labour in its abstract character of human labour, it says that the coat, in so far as it is worth as much as the linen, and therefore is 
value, consists of the same labour as the linen. In order to inform us that its sublime reality as value is not the same as its buckram body, it says that value has the appearance of a coat, and consequently that so far as the linen is value, it and the coat are as like as two peas. We may here remark, that the language of commodities has, besides Hebrew, many other more or less correct dialects. [...] the equating of commodity $B$ to commodity $A$, is commodity A's own mode of expressing its value." (Marx 1867, chapter 1, 11) "The price [...] of commodities is, [...], a purely ideal or mental form. Although invisible, the value of iron, linen and corn has actual existence in these very articles: it is ideally made perceptible by their equality with gold, a relation that, so to say, exists only in their own heads. Their owner must, therefore, lend them his tongue, or hang a ticket on them, before their prices can be communicated to the outside world" (Marx 1867, chapter 3, 1).

Marx presents his ideas about the role of communication in writings ranging from the role of the press in society and the role of the means of communication in social change. His newspaper articles are good examples of political communication that are not reduced down to political campaigns, parliamentary processes and voter attitudes and preferences. He evaluated every important political event all over the world and wrote about the role of communication in the press, politics and public tendencies.

For Marx, technology is not a collection of tools, but technology means society at a certain level of development. Then, means of communication are integral parts of the maintenance and change, and, e.g., played a crucial role in the transition from the feudal mode of production to the capitalist mode, and also within the capitalist mode. Means of communication are employed and used in order to bolster the meaning, limits and potentialities of possible social relations and change.

Marx does not consider means of communication as a mere tool with a specific function: " $A$ house can serve for production as well as for consumption; likewise all vehicles, a ship and a wagon, for pleasure outings as well as a means of transport; a street as a means of communication for production proper, as well as for taking walks" (Marx 1859a).

Marx provided explanations on communication and the relationship of the means of communication with factors that include every aspect of social production, distribution and consumption, maintenance and control of the social formation. His explanations are not limited within the circulation or as merely a certain technological means. Furthermore, it is a grave mistake to expect that Marx would locate communication at the centre of production of life and base his analyses on it or give primacy to the development of communication technology in society and social change ${ }^{6}$.

\section{Development of the Means of Communication and Class Domination}

"all the progress of civilization, or in other words every increase in the powers of social production, if you like, in the productive powers of labour itself - such as results from science, inventions, division and combination of labour, improved means of communication, creation of the world market, machinery etc. - enriches not the worker but rather capital; hence it only magnifies again the power dominating over labour; increases only the productive power of capital' (Marx 1857d, 8).

\section{Communication Facilities and the Magnitude of Productive Supply}

Stating that "a definite quantity of potential productive capital must be available in some quantities for the purpose of entering by and by into the productive process", Marx establishes causal relations that involve communication facilities: "the magnitude of this productive supply depends on the greater or lesser difficulties of its renewal, the relative nearness of markets of supply, the development of transportation and communication facilities" (Marx 1885, chapter 13, 5).

\section{Development of the Means of communication and the Cost of Commodity Transportation}

"The capitalist mode of production reduces the costs of transportation of the individual commodity by the development of the means of transportation and communication, as well as by concentration - increasing scale - of transportation" (Marx 1885, chapter 6, 13).

\footnotetext{
${ }^{6}$ See Harold A. Innis for the powerful function of communication technology in maintenance and social change, Sut Jhally for evaluation of technological determinism, and Marshall McLuhan for effects of communication technology on the human sense organs and the transformation of the world to a global village.
} 
Communication Facilities and the Speed/Time among Processes in Order to Ensure the Continuity of Production

Marx explains this relationship by the example of coal supply: "the rapidity with which the product of one process may be transferred as means of production to another process depends on the development of the transport and communication facilities" (Marx 1885, chapter 6, 8).

\title{
Developed means of Communication and the Density and the Condition of the Division of Labour in Society
}

"A relatively thinly populated country, with well-developed means of communication, has a denser population than a more numerously populated country, with badly-developed means of communication; and in this sense the Northern States of the American Union, for instance, are more thickly populated than India. [...] In consequence of the great demand for cotton after 1861, the production of cotton, in some thickly populated districts of India, was extended at the expense of rice cultivation. In consequence there arose local famines, the defective means of communication not permitting the failure of rice in one district to be compensated by importation from another" (Marx 1867, chapter 14, 9).

\section{Development of the Means of Communication and Season-Work}

"The development of ocean navigation and of the means of communication generally, has swept away the technical basis on which season-work was really supported" (Marx 1867, chapter 15, 30).

\section{Communication and Market Control}

"The cheapness of the articles produced by machinery, and the improved means of transport and communication furnish the weapons for conquering foreign markets" (Marx 1867, chapter 15, 22).

\section{Communication and the Time of Commodity Circulation and Change in Locations of Produc- tion}

Marx explains the role of means of communication in the reduction of commodity circulation time, the growth of social wealth, social relations and change such as the deterioration of old and the rise of new centres of production:

\begin{abstract}
"whereas on the one hand the improvement of the means of transportation and communication brought about by the progress of capitalist production reduces the time of circulation of particular quantities of commodities, the same progress and the opportunities created by the development of transport and communication facilities make it imperative, conversely, to work for ever more remote markets, in a word - for the world-market. The mass of commodities in transit for distant places grows enormously, and with it therefore grows, both absolutely and relatively, that part of social capital that remains continually for long periods in the stage of commodity-capital, within the time of circulation. There is a simultaneous growth of that portion of social wealth which, instead of serving as direct means of production, is invested in means of transportation and communication and in the fixed and circulating capital required for their operation" (Marx 1885, chapter 14, 2).
\end{abstract}

"the improvement of the means of communication and transportation cuts down absolutely the wandering period of the commodities but does not eliminate the relative difference in the time of circulation of different commodity-capitals arising from their peregrinations, nor that of different portions of the same commodity-capital which migrate to different markets. For instance the improved sailing vessels and steamships, which shorten travelling, do so equally for near and distant ports. The relative difference remains, although often diminished. But the relative difference may be shifted about by the development of the means of transportation and communication in a way that does not correspond to the geographical distances. For instance a railway which leads from a place of production to an inland centre of population may relatively or absolutely lengthen the distance to a nearer inland point not connected by rail, as compared to the one which geographically is more remote. In the same way the same circumstances may alter the relative distance of places of production from the larger 
markets, which explains the deterioration of old and the rise of new centres of production because of changes in communication and transportation facilities. (To this must be added the circumstances that long hauls are relatively cheaper than short ones.) Moreover with the development of transport facilities not only is the velocity of movement in space accelerated and thereby the geographic distance shortened in terms of time. Not only is there a development of the mass of communication facilities so that for instance many vessels sail simultaneously for the same port, or several trains travel simultaneously on different railways between the same two points, but freight vessels may clear on consecutive days of the same week from Liverpool for New York, or goods trains may start at different hours of the same day from Manchester to London" (Marx 1885, chapter 14, 1).

\subsubsection{Production of Life: Material Production and the Production of Ideas}

\section{The Production of Material Life}

The nature of and change in the material production of anything, including material means of communication depends on the historical mode of production at a certain time and place. The study of the production of communication primarily includes positioning and analyzing the organized activities within the local, national and international modes, relations and conditions of general production, and the investigation of the history and development of media industries and prevailing practices and conditions of production, distribution and consumption.

For instance, studying the praxis of media production and human conditions as end-products of dominant practices, Marx gives us a striking example in the English letter-press printing trade:

"There existed formerly a system, corresponding to that in the old manufactures and handicrafts, of advancing the apprentices from easy to more and more difficult work. They went through a course of teaching till they were finished printers. To be able to read and write was for every one of them a requirement of their trade. All this was changed by the printing machine. It employs two sorts of labourers, one grown up, renters, the other, boys mostly from 11 to 17 years of age whose sole business is either to spread the sheets of paper under the machine, or to take from it the printed sheets. They perform this weary task, in London especially, for 14, 15, and 16 hours at a stretch, during several days in the week, and frequently for 36 hours, with only 2 hours' rest for meals and sleep. A great part of them cannot read, and they are, as a rule, utter savages and very extraordinary creatures. [...] As soon as they get too old for such child's work, that is about 17 at the latest, they are discharged from the printing establishments" (Marx 1867, chapter 15, 31).

Concerning the relationship between the revolution in the mode of production and the conditions of the means of communication, Marx points out the following connection:

"The revolution in the modes of production of industry and agriculture made necessary a revolution in the general conditions of the social process of production, i.e., in the means of communication and of transport. In a society whose pivot, to use an expression of Fourier, was agriculture on a small scale, with its subsidiary domestic industries, and the urban handicrafts, the means of communication and transport were so utterly inadequate to the productive requirements of the manufacturing period, with its extended division of social labour, its concentration of the instruments of labour, and of the workmen, and its colonial markets, that they became in fact revolutionized. In the same way the means of communication and transport handed down from the manufacturing period soon became unbearable trammels on modern industry, with its feverish haste of production, its enormous extent, its constant flinging of capital and labour from one sphere of production into another, and its newlycreated connections with the markets of the whole world. Hence, apart from the radical changes introduced in the construction of sailing vessels, the means of communication and transport became gradually adapted to the modes of production of mechanical industry, by the creation of a system of river steamers, railways, ocean steamers, and telegraphs. But the huge masses of iron that had now to be forged, to be welded, to be cut, to be bored, and to be shaped, demanded, on their part, cyclopean machines, for the construction of which the methods of the manufacturing period were utterly inadequate" (Marx 1967, chapter 15, 4). 


\section{The Production of Ideas}

According to Marx, the production (and distribution and use) of ideas should be free from any repressive measures. Marx does not consider material production and the production of ideas as two independent spheres. For him, for instance, newspaper production is a business that produces a material thing called the newspaper and sells it; but at the same time, newspaper production is a production of ideas on societal issues. For Marx, ideas are produced and dependent on the conditions of life:

"Men are the producers of their conceptions, ideas, etc. - real, active men, as they are conditioned by a definite development of their productive forces and of the intercourse corresponding to these, up to its furthest forms. Consciousness can never be anything else than conscious existence, and the existence of men is their actual life-process" (Marx 1969, 15).

The following statement explains his most important theoretical and methodological uniqueness that distinguishes him from the idealist philosophy and its new variants with the "post" prefix:

"Life is not determined by consciousness, but consciousness by life. In the first method of approach the starting-point is consciousness taken as the living individual; in the second method, which conforms to real life, it is the real living individuals themselves, and consciousness is considered solely as their consciousness" (Marx 1969, 15) .

\subsection{Marx on Mass Communication}

Marx wrote about every aspect of the press especially in his newspaper articles and personal letters. His interest in media continued until his death. The press was one of the substantial means of political struggle for him as well as the means of capitalist domination.

Marx can be considered a revolutionary political journalist who had the workers' emancipation in mind. Some of his articles in newspapers and letters to newspaper editors show his interest in mass communication and his understanding of communication, public opinion, public communication, press, freedom, freedom of the press, the nature of the relationship between newspapers and the governing power structure (censorship, professional participation in and justification of censorship, and struggle against censorship and participating journals).

His writings in the early 1840s are philosophical and journalistic pieces. They demonstrate Marx's interest in freedom of communication and the use of the press for promoting the ideas of freedom and struggle against censorship, injustice, political oppression, governmental and business corruption. He searched for truth, focused on the real conditions of the social, economic, and political environment and defended the work of journalists and the mission of the press against the pressures coming from the authorities. In his writings in the early 1840s, Marx defended freedom of thought and press and participated in the advancement of the bourgeois liberal revolution against the feudal structures and practices. However, he, after the second half of 1840s, considered press freedom as an emancipatory struggle of the working class and had no positive opinion about the law, press law and the bourgeois democratic parliamentary system. He was involved in the communist movement that struggled for democracy and freedom of the working class. For instance, the last issue of the Neue Rheinische Zeitung was printed entirely in red and contained an editorial notice, thanking the workers of Köln for their participation. The editorial ended with the slogan: "emancipation of the working class". His articles in 1843 were mostly on important current issues, attitudes of other newspapers and government restrictions and sanctions. In 1848 and 1849, he was highly critical of German papers. After moving to England in 1849, he started working as London correspondent of the New York Daily Tribune between 1852-1862. He wrote mostly on politics, war, international relations and government policies.

Marx considered the press as the mythmaking machine and his evaluation holds true more than ever for all the dominant media in the world today:

"Up till now it has been thought that the emergence of the Christian myths during the Roman Empire was possible only because printing had not yet been invented. Precisely the contra$r y$. The daily press and the telegraph, which in a moment spreads its inventions over the whole earth, fabricate more myths in one day (and the bourgeois cattle believe and propagate them still further), than could have previously been produced in a century" (Marx 1871). 


\subsubsection{The Structure of the Media}

Marx does not have any detailed analysis of the media structure, however his articles (e.g., Marx 1861a, 1861b) show how he approaches media ownership, politics and media practices: He goes beyond a simple explanation of ownership. He establishes multiple connections among material interests, the nature of media production and content, and explains the meaning and outcomes of these multiple relational links. He provides information about ownership, explicates the relationship between ownership and politics, relationship between top press professionals and politicians and business interests, connects them with professional practices geared toward propagating and buttressing private and political interests, and clarifies the public's place in it. Here are few instructive excerpts (all from Marx, 1861):

"Continental politicians, who imagine that in the London press they possess a thermometer for the temper of the English people, inevitably draw false conclusions at the present moment. With the first news of the Trent case the English national pride flared up and the call for war with the United States resounded from almost all sections of society. [...] Hence, in the beginning, the peaceful and moderate tone of the London press in contrast to the warlike impatience of the people. So soon, however, as the Crown lawyers [...] had worked out a technical pretext for a quarrel with the United States, the relationship between the people and the press turned into its opposite. The war fever increased in the press in the same measure as the war fever abated in the people. [...]

But now, consider the London press! At its head stands The Times, whose leading editor, Bob Lowe, [...] is a subordinate member of the Cabinet, a kind of minister for education, and a mere creature of Palmerston. [...] A principal editor of Punch was accommodated by Palmerston with a seat on the Board of Health and an annual salary of a thousand pounds sterling. [...]

The Morning Post is in part Palmerston's private property. Another part of this singular institution is sold to the French Embassy. The rest belongs to the haute volée and supplies the most precise reports for court flunkeys and ladies' tailors. [...]

The Morning Advertiser is the joint property of the "licensed victuallers", that is, of the public houses, which, besides beer, may also sell spirits. It is, further, the organ of the English Pietists and ditto of the sporting characters, that is, of the people who make a business of horseracing, betting, boxing and the like. The editor of this paper, Mr. Grant, previously employed as a stenographer by the newspapers and quite uneducated in a literary sense, has had the honour to get invited to Palmerston's private soirees. [...] It must be added that the pious patrons of this liquor-journal stand under the ruling rod of the Earl of Shaftesbury and that Shaftesbury is Palmerston's son-in-law. Shaftesbury is the pope of the Low Churchmen," who blend the spiritus sanctus with the profane spirit of the honest Advertiser. [...]

The Morning Chronicle! [...] For well-nigh half a century the great organ of the Whig Party and the not unfortunate rival of The Times, its star paled after the Whig war. It went through metamorphoses of all sorts, turned itself into a penny paper and sought to live by "sensations", thus, for example, by taking the side of the poisoner, Palmer. It subsequently sold itself to the French Embassy, which, however, soon regretted throwing away its money. It then threw itself into anti-Bonapartism, but with no better success. Finally, it found the long missing buyer in Messrs. Yancey and Mann - the agents of the Southern Confederacy in London. [...]

The Daily Telegraph is the private property of a certain Levy. His paper is stigmatised by the English press itself as Palmerston's mob paper. [...] In the dignity and moderation dictated to it, it seemed so strange to itself that since then it has published half-a-dozen articles about this instance of moderation and dignity displayed by it. As soon, however, as the order to change its line reached it, the Telegraph has sought to compensate itself for the constraint put upon it by outbawling all its comrades in howling loudly for war. [...]

The Tory papers, The Morning Herald and The Evening Standard, both belonging to the same boutique, are governed by a double motive: on the one hand, hereditary hate for "the revolted English colonies"'; on the other band, a chronic ebb in their finances. They know that a war with America must shatter the present coalition Cabinet and pave the way for a Tory Cabinet. With the Tory Cabinet official subsidies for The Herald and The Standard would return. Accordingly, hungry wolves cannot howl louder for prey than these Tory papers for an American war with its ensuing shower of gold! [...]

Of the London daily press, The Daily News and The Morning Star are the only papers left that are worth mentioning; both work counter to the trumpeters of war. The Daily News is re- 
stricted in its movement by a connection with Lord John Russell; The Morning Star (the organ of Bright and Cobden) is diminished in its influence by its character as a "peace-at-anyprice paper". [...] Most of the London weekly papers are mere echoes of the daily press, therefore overwhelmingly warlike. The Observer is in the ministry's pay. The Saturday Review strives for esprit and believes it has attained it by affecting a cynical elevation above "humanitarian" prejudices. To show "esprit", the corrupt lawyers, parsons and schoolmasters that write this paper have smirked their approbation of the slaveholders since the outbreak of the American Civil War. [...]

The Spectator, The Examiner and, particularly, MacMillan's Magazine must be mentioned as more or less respectable exceptions.

One sees: On the whole, the London press - with the exception of the cotton organs, the provincial papers form a commendable contrast - represents nothing but Palmerston and again Palmerston. Palmerston wants war; the English people don't want it. Imminent events will show who will win in this duel, Palmerston or the people. In any case, he is playing a more dangerous game than Louis Bonaparte at the beginning of 1859".

\subsubsection{Freedom and the Media}

The issue of freedom of human beings is the core concern of Marx in his theoretical orientation and all kinds of writings. His newspaper articles show his deep feelings for emancipation of individuals from every kind of oppression and slavery.

For Marx, "freedom remains freedom whether it finds expression in printer's ink, in property, in the conscience, or in a political assembly" (Marx 1842g). "Freedom includes not only what my life is, but equally how I live, not only that I do what is free, but also that I do it freely. Otherwise what difference would there be between an architect and a beaver except that the beaver would be an architect with fur and the architect a beaver without fur?" (Marx 1842f). "Freedom is so much the essence of man that even its opponents implement it while combating its reality; they want to appropriate for, themselves as a most precious ornament what they have rejected as an ornament of human nature" (Marx 1842e). Criticizing those who appropriate freedom for themselves and reject for others, Marx is very explicit:

"these gentlemen, because they want to regard freedom not as the natural gift of the universal sunlight of reason, but as the supernatural gift of a specially favourable constellation of the stars, because they regard freedom as merely an individual property of certain persons and social estates, are in consequence compelled to include universal reason and universal freedom among the bad ideas and phantoms of "logically constructed systems. In order to save the special freedoms of privilege, they proscribe the universal freedom of human nature. Since, however, the bad brood of the nineteenth century, and the very consciousness of the modern knights that has been infected by this century, cannot comprehend what is in itself incomprehensible, because devoid of idea, namely, how internal, essential, universal determinations prove to be linked with certain human individuals by external, fortuitous, particular features, without being connected with the human essence, with reason in general, and therefore common to all individuals -- because of this they necessarily have recourse to the miraculous and the mystical. Further, because the real position of these gentlemen in the modern state does not at all correspond to the notion they have of that position, because they live in a world beyond the real one, and because therefore imagination is their head and heart, being dissatisfied with their practical activity, they necessarily have recourse to theory, but to the theory of the other world, to religion, which in their hands, however, is given a polemical bitterness impregnated with political tendencies and becomes more or less consciously only a holy cloak for very secular, but at the same time fantastic desires" (Marx 1842d).

For Marx:

"every restriction of freedom is a factual, irrefutable proof that at one time those who held power were convinced that freedom must be restricted, and this conviction then serves as a guiding principle for later views" (Marx 1842c). "Whenever one form of freedom is rejected, freedom in general is rejected and henceforth can have only a semblance of existence, since the sphere in which absence of freedom is dominant becomes a matter of pure chance. Absence of freedom is the rule and freedom an exception, a fortuitous and arbitrary occurrence" (Marx 1842g). 


\subsubsection{The Press: Censored and Free Press, Good and Bad Press}

Marx's first interest was in the control of communication, mostly because of his journalistic endeavours starting in the early 1840 s. He provided rich and striking discussions about freedom of the press and censorship in six articles written in May 1842. However, I also included other articles in the study.

Marx considers press as means of public communication and means of struggle for the truth and emancipation. According to him, "the press is the most general way by which individuals can communicate their intellectual being. It knows no respect for persons but only respect for intelligence" (Marx 1842g). He asks, "do you want the ability for intellectual communication to be determined officially by special external signs?" and explicates: "what I cannot be for others, I am not and cannot be for myself. If I am not allowed to be a spiritual force for others, then I have no right to be a spiritual force for myself". He refuses to give "certain individuals the privilege of being spiritual forces" and expounds that "just as everyone learns to read and write, so everyone must have the right to read and write" (Marx 1842g).

He divides the press into two basic groups: those who go along with the authorities and free press (or people's press). Then, he compares their characteristics:

"free press is the ever-present, vigilant eye of the people's spirit, the embodiment of a people's trust in itself, the communication link that binds the individual to state and world, the embodied culture that transforms material struggles into spiritual ones while idealising their crude material form. It is the people's outspoken self-confession, whose redeeming power is well known. It is the spiritual mirror, in which a people discover itself, and insight is the first prerequisite of wisdom. It is the public spirit, which may be delivered to every cottage cheaper than coal gas. It is multifarious, ubiquitous, and omniscient. It is the ideal world, which emerges from the real world only to return to it as an enriched spirit, newly charged" (Marx 1842f).

"The censored press remains bad even when it turns out good products, for these products are good only insofar as they represent the free press within the censored press, and insofar as it is not in their character to be products of the censored press. The free press remains good even when it produces bad products, for the latter are deviations from the essential nature of the free press. The essence of the free press is the characterful, rational, moral essence of freedom. The character of the censored press is the characterless monster of unfreedom; it is a civilised monster, a perfumed abortion" (Marx 1842e).

Marx's following depiction of the censored press reminds us some of the basic tenets of the mainstream popular media today:

"It is the censored press that has a demoralizing effect. Inseparable from it is the most powerful vice, hypocrisy, and from this, its basic vice, come all its other defects, which lack even the rudiments of virtue, and its vice of passivity, loathsome even from the aesthetic point of view. [...] the press lies continually and has to deny even any consciousness of lying, and must cast off all shame. [...] It is the malicious gloating which extracts tittle-tattle and personalities from the great life of the peoples, ignores historical reason and serves up to the public only the scandals of history; being quite incapable of judging the essence of a matter, it fastens on single aspects of a phenomenon and on individuals, and imperiously demands mystery so that every blot on public life will remain hidden. [...] For its part, therefore, the people sinks partly into political superstition, partly into political disbelief, or, completely turning away from political life, becomes a rabble of private individuals" (Marx 1842f).

Marx does not accept the division of press as good press and bad press when the issue is censorship:

"If one wants to speak of two kinds of press, the distinction between them must be drawn from the nature of the press itself, not from considerations lying outside it. The censored press or the free press, one of these two must be the good or the bad press. The debate turns precisely on whether the censored press or the free press is good or bad, i.e., whether it is in the nature of the press to have a free or unfree existence. To make the bad press a refutation of the free press is to maintain that the free press is bad and the censored press good, which is precisely what had to be proved. Base frames of mind, personal intrigues, infamies, occur alike in the censored and the free press. Therefore the generic difference be- 
tween them is not that they produce individual products of this or that kind; flowers grow also in swamps. We are concerned here with the essence, the inner character, which distinguishes the censored from the free press. [...] A free press that is bad does not correspond to its essence. The censored press with its hypocrisy, its lack of character, its eunuch's language, its dog-like tail-wagging, merely realises the inner conditions of its essential nature" (Marx 1842e).

\subsubsection{Freedom of Press, Censorship and Struggle}

There should be material existences of organized entities in specific relationships in order to talk about freedom, domination and struggle. Two such entities are the press and the organized body of censorship. Post-Napoleonic Germany had been promised a constitutionally established string of provincial parliaments. In 1823, Prussia formed eight parliaments (assemblies of the estates). They embraced the heads of princely families, representatives of the knightly estate, i.e., the nobility, of towns and rural communities. It was a parliamentary feudal system under the attack of the liberal bourgeoisie. Marx was part of the revolutionary struggle of the working class and also of the struggle of the bourgeoisie for the advancement of capitalism. Marx fought for freedom and dignity and against the official practices of press control and the manipulation of the truth. Marx identified press practices with the right of freedom of expression that governs the relations between the press and public and private authorities. Marx's articles were occasioned by the censorship instruction of the Prussian Government in December 1841 and the freedom of the press debates in the Rheinland province of Prussia, and they further include a discussion of "the censorship decree in the Provisional Federal Act on the Press" for the German states adopted on September 20, 1819.

Marx considers freedom of the press and censorship as historical fact. For him, the "literary period of strict censorship, is therefore clear historical proof that the censorship has undoubtedly influenced the development of the German spirit in a disastrous, irresponsible way" (Marx 1842c).

The very first article addressing the freedom of the press, censorship and writers was titled "Comments on the latest Prussian Censorship Instructions" and was written between January 15 and February 10, 1842 and published in the Anekdota zur neuesten deutschen Philosophie und Publicistik, in 1843 (Marx 1842a).

Distinguishing himself from those who exclaim "Beware of Greeks bearing gifts" (beware of Trojan horse) even before the appearance of the new Prussian censorship decree, Marx explains that censorship "is official criticism; its standards are critical standards, hence they least of all can be exempted from criticism, being on the same plane as the latter", and the censor "is accuser, defender and judge in a single person; control of the mind is entrusted to the censor" (Marx 1842a). And he continues:

"Censorship is criticism as a monopoly of the government. But does not criticism lose its rational character if it is not open but secret, if it is not theoretical but practical, if it is not above parties but itself a party, if it operates not with the sharp knife of reason but with the blunt scissors of arbitrariness, if it only exercises criticism but will not submit to it, if it disavows itself during its realisation, and, finally, if it is so uncritical as to mistake an individual person for universal wisdom, peremptory orders for rational statements, ink spots for patches of sunlight, the crooked deletions of the censor for mathematical constructions, and crude force for decisive arguments?" (Marx 1842e).

Addressing the nature of the decree, he reminds us that "censorship is also to protect ruling forces from any kind of unwanted communication and criticism: The press is forbidden all control over officials as over such institutions that exist as a class of individuals" (Marx 1842a). Marx declares that the censorship law is not a law: "it is a police measure; but it is a bad police measure, for it does not achieve what it intends, and it does not intend what it achieves" (Marx 1842f).

In his articles, Marx also invalidates each rationale (such as human immaturity, good and bad press, and bad people with bad ideas) given by the speaker of the Assembly in order to justify the censorship. For instance, Marx argues:

"If the immaturity of the human race is the mystical ground for opposing freedom of the press, then the censorship at any rate is a highly reasonable means against the maturity of the human race. Man, individually and in the mass, is imperfect by nature. [...] The arguments of our speaker are imperfect, governments are imperfect, assemblies are imperfect, 
freedom of the press is imperfect, every sphere of human existence is imperfect. Hence if one of these spheres ought not to exist because of this imperfection, none of them has the right to exist, man in general has no right to exist. Amid all these imperfections, why should precisely the free press be perfect? Why does an imperfect provincial estate demand a perfect press? If then, by its very existence, everything human is imperfect, ought we therefore to lump everything together, have the same respect for everything, good and evil, truth and falsehood?" (Marx 1842d).

Invalidating the rationale, Marx continues:

"in order really to justify censorship, the speaker would have had to prove that censorship is part of the essence of freedom of the press; instead he proves that freedom is not part of man's essence. He rejects the whole genus in order to obtain one good species, for is not freedom after all the generic essence of all spiritual existence, and therefore of the press as well? In order to abolish the possibility of evil, he abolishes the possibility of good and realises evil, for only that which is a realisation of freedom can be humanly good. We shall therefore continue to regard the censored press as a bad press so long as it has not been proved to us that censorship arises from the very essence of freedom of the press (Marx 1842d).

Marx also emphasizes that the press freedom has a different character: "Freedom of the press has a justification quite different from that of censorship because it is itself an embodiment of the idea, an embodiment of freedom, a positive good, whereas censorship is an embodiment of unfreedom, the polemic of a world outlook of semblance against the world outlook of essence; it has a merely negative nature". (Marx 1842e).

Marx addresses the repressive conditions in Germany by indicating that twenty two years (since the enactment of the censorship law at the end of 1819) "illegal actions have been committed by an authority which has in its charge the highest interest of the citizens, their minds, by an authority which regulates, even more than the Roman censors did, not only the behaviour of individual citizens, but even the behaviour of the public mind". He provides an excellent discussion on every futile approach to the problem (blaming the censors, individuals, defects in the law or in institutions, nature of the law, newspaper correspondents and public) and concludes: "resentment against the thing itself becomes resentment against persons. It is believed that by a change of persons the thing itself has been changed. [...] The real, radical cure for the censorship would be its abolition; for the institution itself is a bad one, and institutions are more powerful than people" (Marx 1842a).

For Marx, "only struggle can convince both the government and the people, as well as the press itself, that the press has a real and necessary right to existence. Only struggle can show whether this right to existence is a concession or a necessity, an illusion or a truth" (Marx 1843). "Censorship does not abolish the struggle, it makes it one-sided, it converts an open struggle into a hidden one, it converts a struggle over principles into a struggle of principle without power against power without principle" (Marx 1842a).

\subsubsection{The Difference between Press Law and Censorship}

Marx considers censorship law as a precautionary measure of the police against freedom. He compares it with press law in 1842:

"In the press law, freedom punishes. In the censorship law, freedom is punished. The censorship law is a law of suspicion against freedom. The press law is a vote of confidence which freedom gives itself. The press law punishes the abuse of freedom. The censorship law punishes freedom as an abuse. It treats freedom as a criminal, or is it not regarded in every sphere as a degrading punishment to be under police supervision? [...] The press law is a real law because it is the positive existence of freedom. It regards freedom as the normal state of the press, the press as the mode of existence of freedom, and hence only comes into conflict with a press offence as an exception that contravenes its own rules and therefore annuls itself. Freedom of the press asserts itself as a press law, against attacks on freedom of the press itself, i.e., against press offences. The press law declares freedom to be inherent in the nature of the criminal. Hence what he has done against freedom he has done against himself and this self-injury appears to him as a punishment in which he sees a recognition of his freedom. [...] Therefore the press law is the legal recognition of freedom of the press. It constitutes right, because it is the positive existence of freedom. It must therefore exist, even if it is never put into application" (Marx 1842d). 
Marx's positive view of the law had changed within a few years. For instance, in 1848, he considered the Prussian Press Bill as "classic monuments of Napoleonic press despotism" (Padover $1974,121)$. In 1849, he stated that the Prussian despotism was worse than the Napoleonic despotism:

"Prussian despotism, on the other hand, confronts me in the shape of an official with a superior, sacrosanct being. His official character is as integral part of his personality as consecration is of a Catholic priest. [...] To insult such a priest, even one who is not functioning, who is not present, and who is back in private life, remains a profanation of religion, a desecration" (Marx, 1849b).

Marx refuses the claims about the preventive nature of a law. According to Marx, laws

"cannot prevent a man's actions, for they are indeed the inner laws of life of his action itself, the conscious reflections of his life. Hence law withdraws into the background in the face of man's life as a life of freedom, and only when his actual behaviour has shown that he has ceased to obey the natural law of freedom does law in the form of state law compel him to be free, just as the laws of physics confront me as something alien only when my life has ceased to be the life of these laws, when it has been struck by illness. Hence a preventive law is a meaningless contradiction" (Marx 1842d). "A preventive law, therefore, has within it no measure, no rational rule, for a rational rule can only result from the nature of a thing, in this instance of freedom (Marx 1842e).

\subsubsection{Freedom of Press and Freedom of Trade}

Human beings produce and reproduce their material and immaterial life. In regard to the press, Marx clearly explains its role and nature of the relationship between the material and immaterial production in the following sentence: "What makes the press the most powerful lever for promoting culture and the intellectual education of the people is precisely the fact that it transforms the material struggle into an ideological struggle, the struggle of flesh and blood into a struggle of minds, the struggle of need, desire, empiricism into a struggle of theory, of reason, of form" (Marx 1842j). This explanation demonstrates the connection and distinction between the two, but also shows the simplicity and the invalidity of the assertion that Marx/Marxism is an economic reductionist approach and establishes wrong causal relationship between the base and superstructure.

Marx differentiates freedom of the press (journalists' right of free expression) from freedom of trade (right of business): "If the press itself is regarded merely as a trade, then, as a trade carried on by means of the brain, it deserves greater freedom than a trade carried on by means of arms and legs. The emancipation of arms and legs only becomes humanly significant through the emancipation of the brain, for it is well known that arms and legs become human arms and legs only because of the head which they serve" (Marx 1842g).

Marx does not accept the idea that freedom of the press is a part of freedom of trade:

"Freedom of trade, freedom of property, of conscience, of the press, of the courts, are all species of one and the same genus, of freedom without any specific name. But it is quite incorrect to forget the difference because of the unity and to go so far as to make a particular species the measure, the standard, the sphere of other species. This is an intolerance on the part of one species of freedom, which is only prepared to tolerate the existence of others if they renounce themselves and declare themselves to be its vassals. [...] Freedom of trade is precisely freedom of trade and no other freedom because within it the nature of the trade develops unhindered according to the inner rules of its life. [...] Every particular sphere of freedom is the freedom of a particular sphere, just as every particular mode of life is the mode of life of a particular nature. How wrong it would be to demand that the lion should adapt himself to the laws of life of the polyp!" (Marx 1842g).

"To make freedom of the press a variety of freedom of trade is a defence that kills it before defending it, for do I not abolish the freedom of a particular character if I demand that it should be free in the manner of a different character? Your freedom is not my freedom, says the press to a trade. As you obey the laws of your sphere, so will I obey the laws of my sphere. To be free in your way is for me identical with being unfree, just as a cabinet-maker 
would hardly feel pleased if he demanded freedom for his craft and was given as equivalent the freedom of the philosopher" (Marx 1842g).

Acknowledging that "the press exists also as a trade, but then it is not the affair of writers, but of printers and booksellers", Marx pinpoints the crucial difference by stating that "we are concerned here not with the freedom of trade of printers and booksellers, but with freedom of the press. [...] The primary freedom of the press lies in not being a trade" (Marx 1842g).

\title{
5.2.7. Public Rights and Freedom
}

Marx defended the public's right and freedom while defending freedom of the press against the control by the ruling powers. For Marx,

\begin{abstract}
"The law against a frame of mind is not a law of the state promulgated for its citizens, but the law of one party against another party. The law which punishes tendency abolishes the equality of the citizens before the law. It is a law which divides, not one which unites, and all laws which divide are reactionary. It is not a law, but a privilege. One may do what another may not do, not because the latter lacks some objective quality, like a minor in regard to concluding contracts; no, because his good intentions and his frame of mind are under suspicion. The moral state assumes its members to have the frame of mind of the state, even if they act in opposition to an organ of the state, against the government. But in a society in which one organ imagines itself the sole, exclusive possessor of state reason and state morality, in a government which opposes the people in principle and hence regards its anti-state frame of mind as the general, normal frame of mind, the bad conscience of a faction invents laws against tendency, laws of revenge, laws against a frame of mind which has its seat only in the government members themselves. Laws against frame of mind are based on an unprincipled frame of mind on an immoral, material view of the state" (Marx 1842a).
\end{abstract}

\subsubsection{Writers, Professional Practices and Professional Ideologies}

\section{On Writers}

Journalists (and academicians) in their professional practices have mainly one of two choices: The first one is to take the multiple risks and inconveniences and become an ardent follower of the truth. The second one is to run after a multitude of rewards, become a devoted follower and supporter of the status quo. In fact, an internal negotiation happens and the decision depends on mostly the degree of risk the journalist can take.

Marx was the first kind of journalist. For him, journalism is a tool for truth and of the struggle for emancipation. For Marx, "truth is general, it does not belong to me alone, it belongs to all, it owns me, I do not own it. My property is the form, which is my spiritual individuality. [...] Truth includes not only the result but also the path to it. The investigation of truth must itself be true; true investigation is developed truth, the dispersed elements of which are brought together in the result" (Marx 1842a). He despises any practice and law that prescribes the form, the spiritual individuality. Similarly, he also despises any professional practice that follows such a prescribed path.

The second type of journalist is not an honourable professional, even as much as the "dull bureaucrat" who censored Marx's articles. The journalist reproduces the same material and immaterial conditions, but he/she does it knowingly, consciously, premeditatedly and he/she mostly is aware of the fact that $\mathrm{s} / \mathrm{he}$ is distorting, lying or fabricating factoids. However, he/she is not in the same material and mental condition as the dull bureaucrat or the servant-driver of Edward Bernays' Dum Jack (Ewen 1996). The dull bureaucrat named Lauenz Dolleschall would not let anyone "making fun of divine things", thus would censor everything that looks suspicious to him and would say, as Marx quotes: "Now it's a matter of my bread and butter. Now I strike out everything" (cited Quotations are from Padover 1974: xviii). However, the journalist's decisions are not based on his/her irrational or illogical beliefs, but his/her well calculated interest: he/she would edit, thus censor everything that does not fit in his/her interest and interests of his/her employers.

In the defence speech during his trial in 1849, Marx described the duty of the press and journalists:

"I prefer to follow the great events of the world, to analyze the course of history, than to occupy myself with local bosses, with the police and prosecuting magistrates. However great these gentlemen may imagine themselves in their own fancy, they are nothing, absolutely 
nothing, in the gigantic battles of the present time. I consider we are making a real sacrifice when we decide to break a lance with these opponents. But, firstly, it is the duty of the press to come forward on behalf of the oppressed in its immediate neighbourhood. And furthermore, gentlemen, the edifice of servitude has its most specific support in the subordinate political and social powers which directly confront the private life of an individual, of a living person. It is not sufficient to fight against general relationships and the highest authorities. The press must decide to enter the lists against a specific police officer, a specific Public Prosecutor, a specific Landrat. [...] The first duty of the press now is to undermine all the foundations of the existing political state of affairs (Marx 1849b).

The statement above indicates that Marx attributes an important role to the press and journalists in the struggle for freedom. For him, "the press in general is a realisation of human freedom. Consequently, where a press there is freedom of the press". Then, for Marx the question of freedom of the press is not "a question whether freedom of the press ought to exist, for it always exists. The question is whether freedom of the press is a privilege of particular individuals or whether it is a privilege of the human mind. The question is whether a right of one side ought to be a wrong for the other side. The question is whether freedom of the mind has more right than freedom against the mind" (Marx 1842e).

His discussion and explanations on and defence of freedom of thought and communication and of the dignity of a writer are important lessons for certain media professionals (and academicians) who safely practice their daily money making business in shameless compliance with the interest of private and state powers, while other journalists (and academicians) are in jail more than five years without a proper trial for thinking and planning to overthrow the government in countries like Turkey, where a glocal civil dictatorship of global capitalism has been tested. Turkey has more journalists in prison than any other country in the world. More than 100 journalists are currently in prison. There are between 700 and 1,000 ongoing cases in Turkey that could result in more imprisonments and up to 3,000 years imprisonment (http://europe.ifj.org/en/articles?search=Turkey) Mustafa Balbay (a famous journalist and recently elected member of the parliament) and Prof. Dr. Mehmet Haberal (a worldwide famous medical doctor, president of Baskent University and recently elected member of the parliament) have been in jail for more than 3 years for planning a coup against the ruling government. Anyone who writes and says something about the situation is accused of "attempting to influence fair trial" and is put in jail (http://www.dha.com.tr/chp-leaders-immunity-indanger-accused-of-attempting-to-influence-fair-trial-son-dakika-haberi_255874.html). Current dominant professionalism in the media (and academia) is a despicable kind of professionalism that Marx criticizes in his articles.

Marx also sets the basic professional standard for media professionals by differentiating a writer/journalist from a businessperson:

"the writer, of course, must earn in order to be able to live and write, but he must by no means live and write to earn. [...] The writer does not at all look on his work as a means. It is an end in itself, it is so little a means for him himself and for others that, if need be, he sacrifices his existence to its existence. [...] The writer who degrades the press into being a material means deserves as punishment for this internal unfreedom the external unfreedom of censorship, or rather his very existence is his punishment. (May 19, 1842g).

Criticizing the division of authorised and unauthorised writers, Marx asks: "for whom, then, is the division of writers into authorised and unauthorised intended?" and he provides an answer and another question: "Obviously not for the truly authorised, for they can make their influence felt without that. Is it therefore for the "unauthorised" who want to protect themselves and impress others by means of an external privilege?". He adds:

"If the German looks back on his history, he will find one of the main reasons for his slow political development, as also for the wretched state of literature prior to Lessing, in the existence of "authorised writers.". It was the unauthorised writers who created our literature. Gottsched and Lessing-there you have the choice between an "authorised" and "unauthorised" writer! [...] Freedom of the press will certainly not be achieved by a crowd of official writers being recruited by you from your ranks. The authorised authors would be the official authors, the struggle between censorship and freedom of the press would be converted into a struggle between authorised and unauthorised writers" (Marx 1842g). 


\section{On professional practices}

Marx has many statements in articles and letters to editors on the general and daily press practices (e.g.; Marx, 1842h; 1842i; 1842k; 1843; 1843b; 1843c; 1848; 1849; 1860; 1861). They can be grouped as follows:

- Writings about the government persecution of press by imposing a ban on newspapers: Marx questions the legitimacy of such persecutions and the nature of the condition of the press.

- Writings about the reactions of other newspapers and writers on government persecution of the press: Marx criticizes those who have unfair or unjust approaches.

- Remarks, replies, evaluations and criticism of the writings of the other journalists' about an issue, claim, assertion or criticism: Here we see statements ranging from agreement to strong polemics and accusations.

- Evaluation of strategic and/or stylistic exercises of the press.

- Evaluation of the press coverage on politics, relationship between press and politicians, press and people; attitudes of the press on war.

- Evaluation of the press in general.

Observing the attitude of the press towards the official use of repression and censorship measures, Marx heavily criticizes the German press (his assessment fits also e.g. Turkish media today):

"The German daily press is certainly the flabbiest, sleepiest and most cowardly institution under the sun! The greatest infamies can be perpetrated before its very eyes, even directed against itself, and it will remain silent and conceal everything; if the facts had not become known by accident, one would never have learnt through the press what splendid March violets have been brought into being by divine grace in some places" (Marx 1849).

For Marx, the press should protect individuals, but not everybody: "The press is obliged to reveal and denounce circumstances, but I am convinced that it should not denounce individuals, unless there is no other way of preventing a public evil or unless publicity already prevails throughout political life so that the German concept of denunciation no longer exists" (Marx 1843d).

Marx positions the press in society and attributes a mediating role to press between the public and ruling forces. At the same time, he considers the press as an indispensable means of voicing the needs and grievances of the people:

"the rulers and the ruled alike are in need of a third element, which would be political without being official, hence not based on bureaucratic premises, an element which would be of a civil nature without being bound up with private interests and their pressing need. This supplementary element with the head of a citizen of the state and the heart of a citizen is the free press. In the realm of the press, rulers and ruled alike have an opportunity of criticising their principles and demands, and no longer in a relation of subordination, but on terms of equality as citizens of the state; no longer as individuals, but as intellectual forces, as exponents of reason. The "free press", being the product of public opinion, is also the creator of public opinion. It alone can make a particular interest a general one, it alone can make the distressed state of the Mosel region an object of general attention and general sympathy on the part of the Fatherland, it alone can mitigate the distress by dividing the feeling of it among all" (Marx 1843f).

For Marx, the language of the free press is the language of human conditions, not the determining factor of the human life and human relations. He emphasizes the use of language and its connection with the life conditions and bureaucratic report:

"The attitude of the press to the people's conditions of life is based on reason, but it is equally based on feeling. Hence it does not speak only in the clever language of judgment that soars above circumstances, but the passionate language of circumstances themselves, a language which cannot and should not be demanded of official reports. The free press, final$l y$, brings the people's need in its real shape, not refracted through any bureaucratic medium, to the steps of the throne, to a power before which the difference between rulers and ruled vanishes and there remain only equally near and equally far removed citizens of the state" (Marx 1843f). 
The nature of a writer and his/her professional practices indicate his/her professional ideology. The duty Marx assigns to the journalist and press, for instance, in his defence speech above, shows the professional worldview that he aligns himself with. On the other hand, Marx's criticisms about the writers and the press demonstrate the difference between the professional ideology of those who adhere to the dominant mode and relations and those who do not.

\section{Conclusion}

Theory in general is a systematic and consistent explanation of, e.g., organized human practices. Explanations should correspond to the explained, otherwise theory itself or theoretical explanation loses its validity and reliability. However, the validity and reliability can be forged by creating images on the correspondence of theory to practice and on the nature of the practices and/or explanations in such a way that the explanations, despite their irrelevant, inconsistent, inappropriate or incompatible nature, are made valid ones via extensive production, circulation and legitimization practices. Legitimization is done through at least two mechanisms: The first one is to establish domination through inter-subjectivity that is based on rationalized claims of objectivity and, furthermore, universality. The second one is the exercise of power that espouses such inter-subjectivity. Namely, such domination is gained and sustained through organized relations of power and personal interests in a society wherein production and reproduction of material life can be done through the praxis of human agents, who drive their consciousness from the organized material and immaterial life and at the same time, reflect their thinking/consciousness to their material and immaterial conditions. Hence, those who have the power and the means of control have advantages in deciding what, how and where to produce and distribute the material and immaterial products and services. The academic world and the nature of academic production become integral parts of this inter-subjective domination. The findings of the present study clearly indicate that the prevailing nature of academic journals' orientations in issue selection, problem formulation, study objectives, theoretical and methodological approaches carry particular expressions of domination. Most studies published in Media and Communication Studies-journals are various manifestations of mainstream approaches; all are interested in attitudes, interests, preferences and behaviours of individuals and advancing the functionality and interests of corporate and institutional structures. The remaining studies mainly serve as controlled or functional alternatives, with few exceptions. The prevailing dominance of variations of functionalism in communication studies has been discussed by various writers. For instance, Hardt (1997) points out the existence of a dominant functionalist perspective of communication research since the 1940s and a preoccupation with issue orientation based on the practical demands of a growing commercial investment in the media industries. He also indicates that the ideological orientations of U.S. Cultural Studies are determined by liberal-pluralist ideas and that they support commercial-industrial interests that guide the relationship between media and society.

Luring academics to participate and shaping of mental production and relations through the numerous promotional ways and means by the power structures are not new. There are many examples in the communication field: The psychological and cold war warriors (Lasswell, Shills, Lazarsfeld, Cantril, Dewitt, Gallop, Likert, Lerner, Berelson, Schramm, Pool and the like) received millions of dollars for involvement in ideological production and distribution by military and intelligence communities and foundations connected with them (e.g., FBI, CIA, Rockefeller, Ford and Carnegie Foundations, RAND Corporation). Such forms of participation by academicians are still a part of the practice of sustainable domination. There are valuable studies concerning close relations among academicians, state structures and various foundations (e.g., Doob 1947; Schiller 1974; Simpson 1994; Gary 1996; Glander 2000; Solovey 2001; Maxwell 2003; Pooley 2008; Summers 2008; Jonas 2010).

At present, psychological warfare activities and studies are extended to the entire civilian sphere of social life and include multitudes of legitimized and justified relations among multiple parties within a country and at international levels. Early studies with their funding allies helped to shape the formation concept of communication and the direction of the communication field not only in the US, but also throughout the world. Recent studies continue to reproduce the ongoing warfare not only in the political arena, but also in the economic field in order to maintain sustainable development via mind-, interest- and behaviour-management.

One of the important implications of the present study is that participation in networks of profitable relations, the probability of getting financial benefits from various resources, getting formal recognition and success in university departments, finding a reputable place in ruling academic circles, getting published in leading scholarly journals, and getting funds from granting institutions, financing bodies and professional associations require an academic stance that (a) totally ignores 
the Marxist approach, (b) demonstrates an open anti-Marxist stand, (c) engages in trying to invalidate Marxist views by adopting one of the secure and beneficial approaches based on culturalism, post-structuralism, post-modernism, post-positivism and the like, (e) provides mostly wrong and distorted explanations like claiming the demise of Marxism, the end of ideology, democratization, knowledge society, interdependence, decolonisation, identity, and a post-Marxist shift.

\section{The Continuation of Theoretical Domination that Supports Ruling Power Structures}

This study found that theories and methods used in Media and Communication Studies are mostly based on finding effects and developing the mechanisms of control of individual worldviews and behaviours. The dominant effect research has started with a simple model of persuasion and transmission that is characterized by direct and unmediated effects, typically based on persuasion and the audience modelling of observed behaviour. The interest in effects evolved to analytic constructs of audience motivation and disposition of active audience theories such as the elaboration likelihood model, attribution theory, cognitive consistency and selective exposure, and uses and gratifications theory. Adding the contextual context to the individual psychology and/or moving to macro explanations, theories like two-step- and multiple step-flow, diffusion theory, knowledge gaps and social network approaches brought about new research design techniques, especially on qualitative measures, interaction and historical data analysis. Moving to the macro level of design and analysis in the 1970s, the political, economic and institutional context of communication, theories like cultivation theory followed the liberal-democratic critical approach by emphasizing the cultivation of middle class ideology and cumulative effects of the media. For softening the media effects on the audience, theories like agenda setting and media dependency were emerged. Later, agenda melding, priming and framing theories were added to such approaches. In the neo-liberal atmosphere of the 1980s, theories like reception theory, liberal-pluralist cultural studies and identity theories emerged and proliferated alongside the dominant and evolving effects tradition. Concepts like reception, deconstruction, reconstruction and interpretation were put in circulation: The interpretative turn brought back the active and atomized individual. The present study found that such approaches do not receive much interest in most of the journals studied. Proliferation of and support for such approaches takes place in the peripheries of the ruling circles of current research practices. However, Klapper's summary of mass communication research in the 1960s and his suggestions seem still to be a leading guide for most studies in the communication field:

(a) Mainstream orientations focus on various psychological dispositions of audience members;

(b) Culturalists, social interactionists, liberal-pluralists and social psychologists have interests in the situated social context of message reception beyond socio-demographics;

(c) Some post-structuralists focus on the structure of beliefs among audience members, not just the direction of beliefs as it was before;

(d) Audience-reception analysts reintroduce the active audience thesis in a highly elaborate cover and participate in saving the industry from social responsibility.

Klapper's suggestions and the current pseudo-critical and functional alternative research orientations are important because they are all about "knowing people" in detail in order to control them.

Theoretical domination is maintained also through creating functional alternatives and promoting existing functional alternatives. Such maintenance and promotion is evident in academic relations and production. The present study found that the studies that try to totally or partially invalidate Marx or claim that Marxism is waning, inadequate, ethno-centric and insensitive to identities other than class identity are not mainstream or liberal-democrat oriented studies. Mainstream studies ignore and liberal-democrats generally appreciate Marx. The study findings indicate that Marx is not "contested, modified, and deformed, frequently distorted, overstated, and abused by enthusiastic practitioners and promoters" (Artz 2006, 6), but by various kinds of so-called "critical" or "alternative" approaches. The present study could not find any "enthusiastic promoter of Marx/Marxism" in articles, but found that "alternatives" are "alternative to Marx" and the most "critical" ones are in fact "criticism directed against Marx".

Another interesting, let's say "tactic," is that there has been a popular tendency since the late sixties that some writers (for instance, Foucault, Baudrillard, Laclau and Mouffe, and their followers) start with Marx and end with maintaining the invalidation, demise or inadequacy of Marx. This kind of tendency is very popular and fruitful because such mental products are the best mind management and control tools since they pretend to be the current and valid alternative voices (overtly or covertly directed against Marx). 


\section{Reproduction of Theoretical and Methodological Poverty}

The present study also found that most of the studies, especially empirical and pseudo-empirical (survey) studies, seriously lack theoretical reasoning in design, hypothesis construction, and the presentation of conclusions. Similarly, some previous studies found low levels of theory use in Media and Communication Studies (Potter and Riddle 2007; Kamhawi and Weaver 1999). Furthermore, the statements of study objectives are based on meeting the interests of industrial needs for knowing and controlling the audience/consumers and media/knowledge workers.

Such findings support the theoretical reasoning that such scholars only care about issues/problems related to personal and organized-private interests rather than establishing a sound theoretical rationale to explain the nature of any phenomena. Such an orientation further indicates that the academic world is mainly an integrated part of the capitalist industrial structure.

Most qualitative studies that claim that they are doing "discourse analysis" have inconsistent and conflicting theoretical narrations and provide no or no proper information about the way they perform the analysis. Providing many inconsistent theoretical statements and explanations and using highly restricted codes does not reduce or eliminate any uncertainty, rather increases it.

Most of the quantitative studies that use multivariate statistical analysis have no hypotheses that require multi-variate statistical testing. Namely, most hypotheses are hypotheses that are based on bivariate relations, hence require bivariate analysis. Furthermore, there are studies that provide only some questions, but do not extract any hypotheses, but do statistical analysis (including factor analysis or test causal relations without providing a causal hypothesis). All of this means that positivist-empirical research designs, data analysis and findings have serious validity problems.

\section{The Marginalization, Downgrading or Keeping Out of Significant Alternatives, and the Promo- tion of Controlled and Functional Alternatives}

Existence of domination means also the existence of the dominated, which makes domination and struggle for liberation continuous and dynamic. The struggle cannot be a monolithic one, rather it has multiple forms and levels that are interrelated not only with each other, but also with the various expressions of dominant practices. The present study found that there are articles with "critical and highly critical content", however very few can be considered a real/meaningful alternative that is based on, e.g., the idea that societal change means a change in the mode and the relations of production. Almost all of the "critical articles" are overtly or covertly, fully, mostly or generally antiMarxian and are offsprings of, for instance, Durkheim, Heidegger, Husserl, Gadamer, Lacan, Deleuze, Guattari, Foucault, Baudrillard, Said, Habermas, Laclau and Mouffe.

"Criticizing" does not make a theoretical approach critical. "Marx beyond Marx" means a different methodological and theoretical musing if it is not based on Marx's approach. Theoretical approaches that base their main premises on, e.g., the change in the gender composition of parliament, ethnic composition of work force in wage-slavery or obtaining legal recognition of gay marriage are not "alternative orientations" or "critical orientations" because they want acknowledgement by and reintegration into the dominant structure that they criticize. The capitalist system does not become a humane system even if the parliament of capitalism is composed of $100 \%$ women, liberals, leftists or even communists. Then, the move away from class analysis to the current kinds of identity politics is an integral part of the global policy of diversion and "divide and rule". Moving away from the interest in social, economical and ideological/cultural studies and focusing instead on the individual expressions in daily life, away from human beings in organized relations to a constitutive function of textual or other discursive manifestations and the like does not constitute a socially responsible, "critical" and/or Marxian analysis. I consider them, in the final analysis, controlled and/or functional alternatives buttressing the current capitalist mode and relations.

The communication field was established by sociologists, social psychologists, and political scientists. It developed as a social science field. Communication stands at the intersection of every field in the social sciences (an all other sciences). However, it is not a stepchild or colony of scholars of any field who do research and write about communication without first having a sound knowledge about communication. I have been criticizing the situation in Turkey by declaring that the communication field is still colonized by those who do not read even the fundamental literature in communication, are mostly unsuccessful in their own fields and find secure place in the colony (the communication field). In recent years, the communication field has been colonized by the worst kind of outsiders, who are harmfully altering not only communication, but all fields of the social sciences. They come especially from literature, semiotics, and hermeneutics. The situation gets worse by the fact that an increasing number of scholars in communication, who have no background in literature, semiotics, or culture, join the band-wagon by doing cultural studies or dis- 
course analysis. The new colonizers pull especially mass communication away from a field dealing with actual human relations in organized power structures and interest relations towards becoming a field of interpretations of the detached texts and meaningless discourses. Correspondingly, the findings of this study indicate that qualitative communication research is leaving the actual human relations and societal conditions aside and moves towards the analysis of the end products in such a way that the product, process or textual interaction (e.g., language, interpretation, deconstruction, or discourse) is made the "determining agent/factor."

\section{Producing the Material and Immaterial Riches and Poverty ${ }^{7}$}

The nature of domination and struggle in academic relations, as well as in journal- and article- publishing, depends on the historically determined conditions of the mode of production and production relations at a certain time and place. The development of a field and "exchange of scientific ideas" are deeply connected with establishing, sustaining/maintaining and expanding the dominance of intersubjectivities formed by various interest groups gathered around various ideologies/theories and research traditions that provide work security, status and financial enrichment. This dominance of the system of mutual interests involves the control of production and distribution of functional knowledge for the benefit of the system. In the $21^{\text {st }}$ century, power relations and forms of competition within the scientific and research communities have been shaped in such a way that it reached to the point of "science and research in personal interests" which are realized through serving those who pay more in terms of money, fame and status.

There is a dominance of quantitative multitude, qualitative poverty and normalized abnormality in academic journals. Within this frame, the study findings provide support for the fact that there are at least three interrelated dominant immaterial productions (production of ideologies, thoughts, consciousness, beliefs, feelings, emotions, empathy, sensitivity and everything that is not material) in the current global economic and political marketplace.

The first one is the production of knowledge that is based on scientific research for the advancement of capitalist structures and relations. Such knowledge production is rarely done in universities, but mostly in controlled environments like in corporate R\&D departments, private research firms and government institutions. Such knowledge is rarely produced for everybody and the market (not as a commodity); such knowledge is an undisclosed, secret and highly protected product. Such products can be marketed only when advanced knowledge is produced and control mechanisms are established. Such knowledge makes industrial production, advancement and control possible. We cannot see such knowledge in academic journals, unless it is found necessary to establish control and enhance market supremacy ${ }^{8}$. We have no access to them.

The second one is the kind of knowledge that is produced for mind and behaviour management. We can divide this knowledge production into a few sub categories:

(1) Knowledge about people: Such knowledge: This kind of knowledge provides helpful information about people as consumers, customers and voters for industrial and institutional decision and policymaking, implementation, auditing, monitoring and revisions. Marketing, advertising and positivist-empirical communication studies work in this domain.

(2) Knowledge for better work performance: The purpose of this kind of knowledge is to justify the existence of industrial structures and practices, work relations, wage policies and working conditions, and to installs mind-sets and behavioural dispositions that make people work harder and get gratifications from abstract thoughts, feelings, identifications at work. The exam and grading systems in schools prepare students for readily accepting the structural inequalities in the industrial system. Organizational communication studies that focus on communication auditing, sensitivity training, empathy, effective communication, workers' attitudes, behaviour, work performance and relationships at work and the like are designed for manipulation of workers so that there is better performance without raising wages and improving working conditions. Public relation activities within organizations carry the same purpose.

(3) Knowledge for people: This kind of knowledge is provided in order to maintain a certain level and type of consciousness, feelings and sensitivities that justify the conditions of the prevailing mode and relations in life and make people adjust to miserable conditions and ready for accepting individual or mass killings enforced by the ruling forces (Jay Gould's infamous statement saying that "I can hire one half of the working class to kill the other half' has lost validity, because the

\footnotetext{
${ }^{7}$ See for valuable discussions on knowledge and production of knowledge: Marx 1971a; Marx 1973; Marx \& Engels 1969; Carchedi 2005; Fuchs, 2010; Mosco \& McKercher 2008; Mosco 2008; Schiller 1974 and 1987; Schiller 2007; Weiler 2006; Thompson 1997.

${ }^{8}$ See for various discussions: Blackburn 1973; Berube 1996; Allardt 1999; Gunarathe 2010; Fuchs 2010; Tomaselli and Shepperson 2010; Bauer and Jensen 2011.
} 
ruling forces do not have to hire them now since they are already hired and used). Some parts of such knowledge (as in the production and use of emotions, religious and superstitious values) are a continuation of successfully used strategies of ruling forces throughout human history. Such ruling knowledge of previous times are reshaped and reproduced in a country and distributed globally in the same or glocalized forms and used by other dominant classes in other countries. This is one of the essential parts of globalisation of the capitalist mode. Content and significance of this knowledge are not due to its universal validity, but due to the utmost functionality for the ruling interests and practices. For instance, religious ideas and sensitivities that made people refuse to watch television and consider the use of radio and loudspeakers in mosques as a sin in the 1960s, were reversed in 1970s. This is called the integration of the old functional Ideas, structures and practices into the new interests and the ruling mode and relations. This is true not only for the knowledge of people, but also for knowledge for and by professionals throughout the world: Most articles in the 77 journals in this study were written by academicians from all over the world. Other parts of knowledge belong to the current mode of class domination. Whether it has trans-historical character or not, this kind of knowledge is used to sustain all probable kinds of domination over people. Furthermore, knowledge for people is functional for creating "conspicuous consumption" and consumer society, and for establishing a political atmosphere of certain interests, participation, enmity and readiness. This kind of knowledge's aim is to freeze people's intellect and interest at an early teenage level. Such "knowledge" (reproduction of ignorance as knowing) is provided by the mass media, cultural and political organizations and to a varying degree by formal education.

(4) Knowledge for professionals and by professionals: This is the kind of situationally conditioned knowledge that is produced in order to orient the attention, interest, research and educational concerns of scholars towards certain functional professional activities. The activities in daily organizational routines that are based on such knowledge reproduce organizational life. Most mental workers in the production of e.g. a television sitcom can have a false general knowledge about the nature of the product. However, such probability is rather low when it comes to newspaper editors, media professionals and scholars. A scholar is aware of the meaning of a theoretical and methodological choice he/she makes. It is a well calculated or predetermined preference. There is another character of the knowledge and knowledge production under discussion: the number of professional research findings and products that are actually used by the organizational decision makers are at a minimal level. However, most knowledge activities' goal is to keep academicians busy in certain orientations and relational domains. Products of such activities are useless piles of junks for industrial use and, at the same time, extremely useful for the industrial politics of mind and interest control. In this kind of production relations, most academicians are just like football fans: The masses are oriented toward watching or going to football games, the academicians are oriented toward doing research in certain dominant modes. The only difference between the academicians and the masses is that the masses get only psychological satisfaction, while academicians get extra benefits like money and status.

The third one is the production of knowledge on the conditions for knowledge production. We find at least two ruling strategic approaches here: Exclusion and distorted inclusion. One part of this kind of knowledge production has exclusionary character: As it was found in this study, it excludes Marx's (and Marxist) analysis of knowledge production and conditions of knowledge production. This exclusion is done through various mechanisms. The foremost one is the probable productive value or surplus creation probability of the production. For instance, the success of exclusion of an idea is achieved when individuals think that such idea (e.g. learning mass media theory) is useless or that supporting such an idea (e.g. talking about significance of marxist method in communication studies) is not rewarding. The inclusionary character includes various kinds of distortions, invalidations, downgrading, marginalization and inappropriateness.

The explanations about knowledge production above indicate that everyone in various positions in society as an individual and every organized entity participate in production (and dissemination and use) of knowledge. Individuals' knowledge and knowledge of organized entities and the behavioural manifestations are ideologically situated and show the nature of their positions in the class domination and struggle. In the present study, almost all communication scholars with very few exceptions position themselves to serve the interests of the capitalist class. This is most probably because they want to collect the material and immaterial rewards distributed by the same class and also stay away from multiple forms of punishment, which is applied on those who behave differently. They have no interest in the idea of knowledge created, distributed and used for the general interest. Moreover, they are not interested in influencing media practices, policies and taking any urgent social problem as an issue to investigate. 
Such findings also provide support for Marx's conclusions on the nature of the distribution of wealth. The production of wealth is social since everybody participates in the process, but the distribution is private in such a way that a small number of people who own and control the means of production appropriate most of the wealth. The same problem exists in the production, distribution and use of knowledge: The distribution of wealth in terms of material gains and in terms of functional knowledge is highly controlled.

\section{Extending the Prevailing Structure of Interests and Relations to the New Media}

The present study found that most historically prevailing issues, problems, concerns, ideologies, methods and theories are also carried to and used in the new computer-mediated communication research. The similar mystifications and functional discussions we witnessed during the 1960s about television are reproduced about the Internet.

There are new issues and data collection techniques, because of the nature of new personal communication technologies like mobile phones and computer-mediated communication. However, they are only tools for the implementation of organized objectives, hence they do not change or abandon the prevailing ideological and material interests. Some new issues are renewed oldissues like the role and effects of the new media. There are also mystified new terms like social media, as if the other media are not social, not economical and not directorial and administrative. In fact, all new media are social, economical, industrial, administrative and directional. Technological multi-directionality does not make a communicative action democratic or symmetrical or two-way; a mobile phone is a multi-directional device a lot more than the Internet in terms of permitting a two or multi-sided flow. However, it is not the mobile phone or Internet that determines the nature of relations. The determining factor is the structured nature of power relations and interests. Two ways or multiple ways of a technological device cannot change the nature of power relations and the nature of communication. The mobile phone does not change the mode of relations between you and your boss, and does not alter the fact that your boss is your boss. Democratic relations and freedom of communication are impossible if any of the following determining factors are missing, banned or exercised by only one side. It does not matter if you use the Internet or the mobile phone or not, you are not free and your communication is not symmetrical or democratic if you cannot:

(1) start or stop the communication

(2) organize or influence the organization of time, place and conditions of interaction

(3) fill, modify and change the content of communication as you wish

(4) change or stop the nature of flow during the interaction (for instance, change the subject)

(5) end the communication at any point

(6) exert influence on the objective and outcome beyond being a mere participant

You can participate in every political discussion on the Internet; such participation does not make a political system a democratic system and such a use does not mean that the Internet is an agent of democratisation, since you cannot exert influence on the issues to be discussed, collective political decisions to be taken, implementations to be taken and the benefits to be divided/shared. The Internet is the most recent means of economical, political, mental, emotional and behavioural control; a newly added and improved popular opium of the people - especially of the young generation that is the most likely danger for the system. In essence, it is the new sphere of domination, control and struggle.

It is hard to find an Internet study that investigates the ways in which structure and use of Internet technologies worsens social inequities in terms of labour practices, distribution of wealth, and state surveillance activities, opens new ways of domination and struggle. However, there are many studies on the Internet's role in participatory democracy, bottom-up political forms (as if such forms were possible under the prevailing political structures). Many of them are eulogies to activist groups, the democratic underground, democratic and partisan public spheres. I must repeat that using communications media does not mean that we have reached or that we are at the level of participatory democracy. Participatory democracy or empowerment does not mean "use or consume" in a specific manner. Participating in consumption or use (including use for "writing, authorship") never means a democratic participation in daily life or empowerment as long as we are kept out of the power structure, as long as we are unable to influence the decision-making processes and ruling practices of the dominant forces. Did anybody change his/or her wage or working conditions through the Internet? I reiterate that the Internet is not a tool of emancipation, but a tool of dominance and struggle. We now have an additional medium controlled by economic and political interests. it is another contemporary field and means of struggle against dominance that has dramatically increased opportunities to observe us 24 hours. 


\section{Recommendations}

Recommendations are useful only for those, who are in the habit of questioning himself/herself and anything and everything in life, and have no affect on those who align their own interest with those who pay the pipers, since they do not read articles like the present one. Those who read either are supporters, sympathizers or concerned by the Marxist approach. Some read just to know as much as possible. Some others read to collect information about the Marxist enemy. In any case, my recommendations based on the current study and accumulated knowledge are as follow:

Some studies have serious theoretical conceptual and methodological problems. Those who are not from the communication field, but conduct a study about communication, should first read the fundamental texts in communication studies beyond simple prescriptions of sender-messagechannel-receiver-effect understandings and similar misconceptions. Those, who have a communication background, should either stay away from the popularized interest in cultural studies, discourse anaysis, reception analysis, semiotics and the like or firstly gain necessary knowledge about, e.g., semiotics and methods in semiotics. Furthermore, it is part of academic decency not to do any evaluation and ignore the most basic textual context such as words like "in general", the sentence before or after a sentence. I also suggest that we should read the original sources if the issue is a person like Marx, who has been widely distorted.

Some studies have serious problems in choosing the socially significant issues, theory and method. This is mostly because of the prevailing nature of academia. I suggest it is time to start to question the dominant orientations and to study Marx's theoretical and methodological approach in search of significant ways for understanding the nature of communication in society and societal change. The functionalist theoretical approaches and their current versions and their explicit and implicit assumptions and outcomes for the organized human life and environment have been well documented and their resonance can still be felt in current communication scholarship. In light of this multifaceted dominance, a basic advantage of Marx's approach is that it provides a lot better theoretical and methodological means and ways of social inquiry. At the same time, it leads us to study socially significant issues with most meaningful manner by including all probable contextual determinants in understanding the nature of production, distribution and consumption of communication products, control, subversion, coercion, domination and struggle.

Marx's approach can enable a systematic study of communication across multiple levels of relationships/interaction and analyses, ranging from the individual to the global level. No approach has been valid enough to be able to facilitate the study of prevailing conditions, development and change. For instance, modernization/development studies based on equilibrium, structural functionalist or behaviourist approaches and their current versions do not only fall short in explanations, but also tend to create mystifications and factoids about media and communication related issues. Recent global crises also mean the crisis of prevailing dominant and neo-dominant approaches in sociology, political science, economics and communication. Hence, despite all the produced obstacles, Marx's approach remains the most viable approach to the study of any kind of communication, especially mass communication.

Although there are studies that have generated insightful theoretical, conceptual and practical explanations, there is still a growing need for better understanding of Marx and his contributions to the study of communication. Doing so, studying from time to time the nature of research orientations in Media and Communication Studies is an important and constructive academic initiative. Scholarly discussions on the status of the field, its historical development and its nature are a necessary outcome of such activity.

I believe that any initiative of Marxist scholars in the publishing and tenure environment is a meaningful and important contribution to Marxist Communication Studies and the communication field, given that even the use of the name of Marx can result and has historically often resulted in repression.

\section{References}

Adakli, Gülseren. 2009. The Process of Neo-Liberalization and the Transformation of the Turkish Media Sector in the Context of the New Media Architecture. In Jackie Harrison, and Bridgitte Wessels (eds.) Mediating Europe: New Media, Mass Communications. N. Y.: Berghahn Books.

Allardt, Erick. 1999. The Future of the Social Sciences in the 21st Century - A Comment. Current Sociology 47 (4): 13-17. Babe, Robert. The Political Economy of Knowledge: Neglecting Political Economy in the Age of Fast Capitalism (as Before). Accessed February 4, 2012. http://www.uta.edu/huma/agger/fastcapitalism/2 1/babe.htm

Babbie, Earl R. 2004. The Practice of Social Research. 10th ed. Belmont, CA: Wadsworth.

Bagdikian, Ben H. 1997. The Realities of Media Concentration and Control. Television Quarterly 29 (3): 22-28.

Bauer, Martin W., and Pablo Jensen. 2011. The Mobilization of Scientists for Public Engagement. Public Understanding of Science. 20 (1): 3-11. 
Berube, Michael. 1996. Cultural Criticism and the Politics of Selling Out. Accessed January 28, 2012. http://www.altx.com/ebr/ebr2/2berube.htm

Berube, Michael, and Cary Nelson.1995. Higher Education under Fire: Politics, Economics, and the Crisis of the Humanities. New York: Routledge.

Blackburn, Robin. 1973. Ideology in Social Sciences. New York: Pantheon.

Bodemann, Y. Michal. 1979. The Fulfilment of Fieldwork in Marxist Praxis. Dialectical Anthropology 4 (2): 155-161.

Boyer, Richard O., and Herbert M. Morais. 1965/1980. Labor's Untold Story. New York: UE.

Carchedi, Guglielmo. 2005. On the Production of Knowledge. In The Capitalist State and Its Economy: Democracy in Socialism (Research in Political Economy, Volume 22), edited by Paul Zarembka, 267-304. Bingley: Emerald Group Publishing Limited.

Cerwonka, Allaine. 2009. Higher Education 'Reform', Hegemony, and Neo-Cold War Ideology. Cultural Studies 23 (5-6): 720-735.

Chouliaraki, Lilie, and Norman Fairclough. 1999. Discourse in Late Modernity: Rethinking Critical Discourse Analysis. Edinburgh: Edinburgh University Press.

Dei, George J. S., and Gurpreet S. Johal. 2005. Critical Issues in Anti-Racist Research Methodologies. New York: Peter Lang.

Dyer-Witheford, Nick. 1999. Cyber-Marx: Cycles and Circuits of Struggle in High-Technology Capitalism. Urbana, IL: University of Illinois Press.

Domenech, Antoni. 2009. University Autonomy, a Return to the Thirties. Accessed January 12, 2012. http://www.barcelonametropolis.cat/en/page.asp?id=23\&ui=148\#

Doob, Leonard. 1947. Utilization of Social Scientists in the Overseas Branch of the Office of War Information. American Political Science Review 41 (4): 49-67.

Dorfman, Ariel.1983. The Empire's Old Clothes. New York: Pantheon.

Ewen, Stuart. 1996. PR! A Social History of Spin. New York: BasicBooks.

Fetscher, Iring, ed. 1969. Karl Marx - Friedrich Engels. Pressefreiheit und Zensur. Frankfurt: Europäische Verlagsanstalt.

Fuchs, Christian. 2010. Class, Knowledge and New Media. Media, Culture \& Society 32 (1): 141-150.

Fuchs, Christian. 2010a. Grounding Critical Communication Studies: An Inquiry into the Communication Theory of Karl Marx. Journal of Communication Inquiry 34 (1): 15-41.

Fuchs, Christian. 2011. An Alternative View of Privacy on Facebook. Information 2: 140-165. Accessed February 7, 2012. http://fuchs.uti.at/489/

Fuchs, Christian. 2011. Foundations of Critical Media and Information Studies. New York: Routledge.

Gans, Herbert. 1975. Social Science for Social Policy. In The Use and Abuse of Social Sciences, edited by Irvin L. Horowitz, 3-23. New Brunswick, New Jersey: Transaction Books.

Garnham, Nicholas. 2001. The Information Society: Myth or Reality. Accessed January 12, 2012. http://www.er.uqam.ca/nobel/gricis/actes/bogues/Garnham.pdf

Gary, Brett. 1996. Communication Research, the Rockefeller Foundation, and Mobilization for the War on Words. Journal of Communication 46 (3): 124-147.

Glander, Timothy R. 2000. Origins of Mass Communications Research during the American Cold War: Educational Effects and Contemporary Implications. Mahwah, NJ: Erlbaum.

Gorz, Andre. 1980. On the Class Character of Science and Scientists. In Ideology of/in the Natural Sciences, edited by Hillary Rose and Steven Rose, 59-71. Cambridge, MA: Scenkman Publishing.

Golding, Peter. 2000. Forthcoming Features: Information and Communications Technologies and the Sociology of the Future. Sociology 34 (1): 165-184.

Grossberg, Lawrence. 1997. Bringing It All Back Home: Essays on Cultural Studies. London: Duke University Press.

Gunaratne, Shelton. A. 2010. De-Westernizing Communication/Social Science Research: Opportunities and Limitations. Media, Culture and Society 32 (3): 473-500.

Hardt, Hanno. 1997. Beyond Cultural Studies - Recovering the 'Political' in Critical Communications Studies. Journal of Communication Inquiry 21 (2): 70-79.

Hardt, Hanno. 2000. Communication is Freedom: Karl Marx on Press Freedom and Censorship. Javnost - The Public 7 (4): $85-100$.

Haye, Yves de la. 1980. Marx and Engels on the Means of Communication. Paris: International General

Jhally, Sut. 1993. Communications and the Materialist Conception of History: Marx, Innis and Technology. Continuum: The Australian Journal of Media \& Culture 7 (1). Accessed December 2, 2011. http://wwwmcc.murdoch.edu.au/ReadingRoom/7.1/Jhally.html

Jonas, Marie. 2010. A Short History of the Relationship between the American Psychological Association and the U.S Military. hhttp://www.law.berkeley.edu/historyofAPAandMilitarypaper(final)11June10.pdf

Kamhawi, Rasha, and David Weaver. 2003. Mass Communication Research Trends from 1980 to 1999. Journalism \& Mass Communication Quarterly 80 (7): 7-27.

Klapper, Joseph. T. 1960. The Effects of Mass Communication. Glencoe, III: Free Press.

Martin, Brian. 1998. Tied Knowledge: Power in Higher Education. Accessed January 7, 2012. Http://www.bmartin.cc/pubs/98tk/tk02.html

Marx, Karl. 1842a. Comments on the Latest Prussian Censorship Instruction. Accessed January 13, 2012. http://www.marxists.org/archive/marx/works/1842/02/10.htm

Marx, Karl. 1842b. Prussian Censorship. Accessed December 10, 2011. Http://www.marxists.org/archive/marx/works/1842/free-press/ch01.htm

Marx, Karl. 1842c. Opponents of a Free Press. Accessed December 10, 2011. http://www.marxists.org/archive/marx/works/1842/free-press/ch02.htm

Marx, Karl. 1842d. On the Assembly of the Estates. Accessed December 10, 2011. http://www.marxists.org/archive/marx/works/1842/free-press/ch03.htm

Marx, Karl. 1842e. As a Privilege of Particular Individuals or a Privilege of the Human Mind?. (May 12) Accessed December 10, 2011. http://www.marxists.org/archive/marx/works/1842/free-press/ch04.htm 
Marx, Karl. 1842f. Censorship. Accessed December 10, 2011. http://www.marxists.org/archive/marx/works/1842/freepress/ch05.htm

Marx, K. 1842g. Freedom in General. Accessed December 10, 2011. Http://www.marxists.org/archive/marx/works/1842/free-press/ch06.htm

Marx, Karl. 1842h. Editorial Note: Communism and the Augsburg Allgemeine Zeitung. Accessed January 10, 2012. http://www.marxists.org/archive/marx/works/1842/10/22.htm

Marx, Karl. 1842j. The Supplement to Nos. 335 and 336 of The Augsburg Allgemeine Zeitung on the Commissions of the Estates in Prussia. Accessed December 3, 2012 http://www.marxists.org/archive/marx/works/1842/12/10.htm

Marx, Karl. 1842k. The Polemical Tactics of the Augsburg Newspaper. Accessed November 28, 2011. http://www.marxists.org/archive/marx/works/1842/11/29a.htm

Marx, Karl. 1843. The Ban on the Leipziger Allgemeine Zeitung. Http://www.marxists.org/archive/marx/works/1842/12/31.htm

Marx, Karl. 1843b. Polemical Articles against The Allgemeine Zeitung. Accessed November 28, 2011. http://www.marxists.org/archive/marx/works/1843/01/03.htm

Marx, Karl. 1843c. Stylistic Exercises of the Rhein- und Mosel-Zeitung. Accessed November 28, 2011. http://www.marxists.org/archive/marx/works/1843/03/13.htm

Marx, Karl. 1843d. Cabinet Order on the Daily Press. Accessed January 15, 2012 http://www.marxists.org/archive/marx/works/1842/11/16a.htm

Marx, Karl. 1843f. Justification of the Correspondent from the Mosel. Accessed January 12, 2012. http://www.marxists.org/archive/marx/works/1843/01/15.htm

Marx, Karl. 1843g. Justification of the Correspondent from the Mosel. Accessed January 12, 2012. http://www.marxists.org/archive/marx/works/1843/01/15.htm

Marx, Karl. 1848. Articles by Marx and Engels in Neue Rheinische Zeitung http://www.marxists.org/archive/marx/works/subject/newspapers/neue-rheinische-zeitung.htm

Marx. Karl. 1848a. Communist Manifesto. http://www.marxists.org/archive/marx/works/1848/communist-manifesto/ch02.htm

Marx, Karl. 1849. The Censorship. Accessed November 28, 2011. http://www.marxists.org/archive/marx/works/1849/03/15b.htm

Marx, Karl. 1849b. Speech by Karl Marx: The First Trial of the Neue Rheinische Zeitung. Accessed November $28,2011$. http://www.marxists.org/archive/marx/works/1849/02/07.htm

Marx, Karl. 1853. The War Question. New-York Daily Tribune, No. 3904. Accessed October 21, 2009. http://csf.colorado.edu/mirrors/marxists.org/archive/marx/works/nydt/531021.htm

Marx, Karl. 1853b. Revolution in China and Europe. New York Daily Tribune 14 June. Marxists Internet Archive, http://www.marxists.org/archive/marx/works/1853/06/14.htm

Marx, Karl. 1853c. Revolution in China and Europe. New York Daily Tribune 14 June, Marxists Internet Archive, http://www.marxists.org/archive/marx/works/1853/06/14.htm

Marx, Karl. 1854. Declaration of War. - On the History of the Eastern Question. New-York Daily Tribune, April 15. Accessed November 25, 2011. http://www.marxists.org/archive/marx/works/1854/03/28.htm

Marx, Karl. 1857. Russian Trade with China. New York Daily Tribune 7 April, Marxists Internet Archive, http://www.marxists.org/archive/marx/works/1857/04/07.htm

Marx, Karl. 1857a. Introduction to a Contribution to the Critique of Political Economy, Appendix I. Accessed November 23 2011. http://www.marxists.org/archive/marx/works/1859/critique-pol-economy/appx1.htm

Marx, Karl. 1857b. The Revolt in India. New-York Daily Tribune, September 15. Accessed Nevember 25, 2011. http://www.marxists.org/archive/marx/works/1857/09/15.htm

Marx, Karl. 1857d. The Grundrisse: Notebook III. The Chapter on Capital (Continuation). Accessed January $15,2012$. http://www.marxists.org/archive/marx/works/1857/grundrisse/ch06.htm

Marx, Karl. 1859. Critique of Political Economy. Accessed November 25, 2011. http://www.marxists.org/archive/marx/works/1859/critique-pol-economy/ch02 4.htm

Marx, Karl. 1859a. Grundrisse: Threefold Character, or Mode, of Circulation. Accessed December $13,2011$. http://www.marxists.org/archive/marx/works/1857/grundrisse/ch13.htm\#p678

Marx, Karl. 1860. Letter to the Editor of the Free Press: Prosecution of the Augsburg Gazette. Accessed December 3,2012 http://www.marxists.org/archive/marx/works/1860/02/04.htm

Marx, Karl. 1961. The Opinion of the Newspapers and the Opinion of the People. Accessed January 13, 2012. http://www.marxists.org/archive/marx/works/1861/12/31.htm

Marx, Karl. 1861a. The North American Civil War (Collection of Articles). Accessed February 13, 2012. http://libcom.org/library/american-civil-war-karl-marx

Marx, Karl. 1863-1883. Capital Volume III. Accessed November 25, 2011. http://www.marxists.org/archive/marx/works/1894-c3/ch39.htm

Marx, Karl. 1964. Selected Writings in Sociology and Social Philosophy. (Translated by T.B. Bottomore). London: McGraw-Hill.

Marx, Karl. 1867. Capital Volume I. Accessed November 25, 2011. http://www.marxists.org/archive/marx/works/1867c1/index.htm

Marx, Karl. 1971a. The Economic and Philosophic Manuscripts of 1844. N.Y: International Publishers.

Marx, Karl. 1871. Letter to Ludwig Kugelmann. Accessed January 12, 2012. http://solomon.tinyurl.alexanderstreet.com/cgibin/asp/philo/soth/getdoc.pl?S10022522-D000107

Marx, Karl. 1973. Grundrisse: Foundations of the Critique of Political Economy. London: Penguin.

Marx, Karl. 1975. Contribution to the Critique of Hegel's Philosophy of Law. Early Writings. London: Penguin.

Marx, Karl. 1976. Capital. Vol. I, Harmondsworth: Penguin Books.

Marx, Karl. 1977. Preface to A Contribution to the Critique of Political Economy. Moscow: Progress Publishers.

Marx, Karl. 1885. Capital Volume II. Accessed December 13, 2011. http://www.marxists.org/archive/marx/works/1885c2/index.htm 
Marx, Karl, and Frederick Engels. 1846. The German Ideology. Accessed December 13, 2011. http://www.marxists.org/archive/marx/works/1845/german-ideology/ch01c.htm

Marx, Karl, and Friedrich Engels. 1962. Selected Works, 2 vols. Moscow: Foreign Language Publishing House. http://www.marxists.org/archive/marx/works/1890/letters/90_09_21.htm

Marx, Karl, and Frederick Engels. 1965. Selected Correspondence (1955). 2nd ed. Moscow: Progress.

Marx, Karl, and Frederick Engels. 1969. The German Ideology. New York: International Publishers.

Mattelart, Armand, and Seth Siegelaub. 1979. Communication and Class Struggle: Capitalism, Imperialism. Bagnolet: International Mass Media Research Center.

Maxwell, Richard. 2003. Herbert Schiller. Lanham, MD: Rowman and Littlefield Publishers.

Maxwell, Richard. 2001. The Political Economy of Culture. Minneapolis, MN: University of Minnesota Press.

McChesney, Robert W. 2008. The Political Economy of the Media: Enduring Issues, Emerging Dilemmas. New York: Monthly Review Press.

Mingers, John. 1996. A Comparison of Maturana's Autopoietic Social Theory and Giddens' Theory of Structuration. Systems Research 13 (4): 469-482.

Mosco, Vincent. 1982. Pushbutton Fantasies. Norwood, N.J.: Ablex Publishing

Mosco, Vincent. 1996/2009. The Political Economy of Communication: Rethinking and Renewal. London: Sage.

Mosco, Vincent. 2004. The Digital Sublime: Myth, Power, and Cyberspace. Cambridge, MA: The MIT Press.

Mosco, Vincent, and Catherine McKercher. 2008. The Laboring of Communication: Will Knowledge Workers of the World Unite? New York: Lexington Books

Mosco, Vincent. 2008. Knowledge Workers of the World! Unite? Communication, Culture \& Critique 1 (1): 105-115.

Murdock, Graham and Peter Golding. 1977. Capitalism, Communication and Class Relations. In Mass Communication and Society, edited by James Curran, Michael Gurevitch and Janet Woollacoot, 12-43 . London: Arnold.

Murdock, Graham and Peter Golding. 1978. Theories of Communication and Theories of Society. Communication Research 5 (3): 339-356.

Padover, Saul K., ed. 1979. The Letters of Karl Marx. Englewood Cliffs, NJ: Prentice-Hall.

Padover, Saul. K., ed.1974. On Freedom of the Press and Censorship. New York: McGraw-Hill.

Philo, Greg, and David Miller. 2000. Cultural Compliance and Critical Media Studies. Media, Culture and Society 22 (6): 831-839. Accessed January 15, 2012. http://www.glasgowmediagroup.org/content/view/3/

Pooley, Jeferson. 2008. The New History of Mass Communication Research. In The History of Media and Communication Research: Contested Memories, edited by David Park and Jefferson Pooley, 43-69. New York: Peter Lang.

Potter, W. James, and Karyn Riddle. 2007. A Content Analysis of the Media Effects Literature. Journalism and Mass Communication Quarterly 84 (1): 90-104.

Potter, W. James, Roger Cooper, and Michel Dupagne. 1993. The Three Paradigms of Mass Media Research in Mainstream Journals. Communication Theory 3 (4): 317-335.

Riffe, Daniel, and Alan Freitag. 1997. A Content Analysis of Content Analyses: Twenty-Five Years of Journalism Quarterly. Journalism \& Mass Communication Quarterly 74 (4): 873-882.

Schiller, Dan. 2003. End of the Telecom Revolution. Le Monde Diplomatique English Edition, August 2003. Accessed January 10, 2011. http://mondediplo.com/2003/08/08schiller

Schiller, Dan. 2000. Digital Capitalism. Cambridge, MA: The MIT Press.

Schiller, Dan. 2007. How to Think About Information. Urbana, IL:: University of Illinois Press.

Schiller, Dan. 1993. Capitalism, information and Uneven Development. In Communication Yearbook 16, edited by Stanley A. Deetz, 386-406. Newbury Park, CA: Sage.

Schiller, Dan. 1982. Telematics and Government. Norwood, NJ: Ablex Publishing.

Schiller, Herbert I. 1971. Mass Communications and American Empire. Boston, MA: Beacon Press.

Schiller, Herbert I. 1974. Mind Managers. Boston, MA: Beacon Press.

Schiller, Herbert I. 1987. Culture Inc.: The Corporate Takeover of Public Expression. New York: Oxford University Press.

Schiller, Herbert I. 1991. Culture, Inc. The Corporate Takeover of Public Expression. New York: Oxford University Press.

Schiller, Herbert I. 1992. Mass Communications and American Empire. Boulder, CO: Westview Press.

Schiller, Herbert I., and Ithiel de Sola Pool. 1981. Perspectives on Communications Research: An Exchange. Journal of Communication 31 (3): 15-23.

Shaw, Donald. L., Bradley J. Ham, and Diana L. Knott. 2000. Technological Change, Agenda Challenge and Social Melding: Mass Media Studies and the Four Ages of Place, Class, Mass and Space. Journalism Studies 1 (1): 57-79.

Simpson, Christopher. 1994. The Science of Coercion: Communication Research and Psychological Warfare 1945-1960. New York: Oxford University Press.

Smythe, Dallas W. 1982. Dependency Road: Communications, Capitalism, Consciousness, and Canada. Norwood, NJ: Ablex Publishing.

Solovey, Mark. 2001. Project Camelot and the 1960s Epistemological Revolution: Rethinking the Politics-Patronage-Social Science Nexus. Social Studies of Science 31 (2): 171-205.

Summers, Frank. 2008. Making Sense of the APA: A History of the Relationship between Psychology and the Military. Psychoanalytic Dialogues 18 (5): 614-637.

Therborn, Göran. 1976. Science, Class and Society. London: New Left Books.

Thompson, Herb. 1997. Ignorance and Ideological Hegemony: A Critique of Neoclassical Economics. Journal of Interdisciplinary Economics 8 (4): 291-305.

Tomaselli, Keyan G., and Arnold Shepperson. 2010. All the World's Brothel Metaphysics of the Text and Cultural Economy in the Information Age. Critical Arts 24 (1): 51-74.

Wasco, Janet, Graham Murdock and Helena Sousa, eds. 2011. The Handbook of Political Economy of Communications. Malden, MA: Wiley-Blackwell. 


\section{About the Author}

Irfan Erdogan

is Professor in the Faculty of Communication at Gazi University, Ankara, Turkey. He has published books and articles regarding theoretical, methodological, ideological, cultural and political economy aspects of mass communication. Currently he is working on research about the theoretical and methodological orientations of current media studies and on a book based on a study of the nature of television programs. 